\title{
9,10-Phenanthrenequinone: A Promising Kernel to Develop Multifunctional Antitumor Systems for Efficient Type I Photodynamic and Photothermal Synergistic Therapy
}

Jingjing Guo, ${ }^{*}$ Jun Dai, ${ }^{*}$ Xiaoluo Peng, Quan Wang, Shixuan Wang, Fan Xia, Zujin Zhao,* Xiaoding Lou and Ben Zhong Tang

\section{General information}

All the chemicals and reagents were purchased from commercial sources and used as received without further purification. In vitro and in vivo experiments, 1,2-distearoyl-sn-glycero-3-phosphoethanolamine- $N$-[methoxy-(polyethylene glycol)-2000] (DSPE-mPEG2000) was purchased from Sigma; dihydroethidium (DHE) was purchased from YEASEN (Shanghai, China); 2,7-dichlorodihydrofluorescein diacetate (DCFH-DA) was purchased from Aladdin. Propidium iodide (PI) and Cell Counting Kit-8 (CCK8) were purchased from Beyotime Biotechnology (China). CellTracker ${ }^{\mathrm{TM}}$ Green CMFDA Dye was purchased from Thermo Fisher (China). TUNEL BrightGreen Apoptosis Detection Kit was purchased from Vazyme (China). C-caspase3 and Ki-67 antibody were purchased from Biossci (Wuhan, China). Immunohistochemistry kit was purchased from ZSGB-BIO (Beijing, China).

${ }^{1} \mathrm{H}$ and ${ }^{13} \mathrm{C}$ NMR spectra were measured on the Bruker AV 500/400 spectrometer in $\mathrm{CDCl}_{3}$ at room temperature. High-resolution mass spectra (HRMS) were recorded on Thermo Scientific Q Exactive. Single crystal X-ray diffraction intensity data were collected at $173 \mathrm{~K}$ on a Bruker-Nonices Smart Apex CCD diffractometer with graphite monochromated MoK $\alpha$ radiation. Processing of the intensity data was carried out using the SAINT and SADABS routines, and the structure and refinement were conducted using the SHELTL suite of X-ray programs. The corresponding data (PQ-TPA: CCDC 2087038) can be obtained free of charge from The Cambridge Crystallographic Data Centre. Cyclic voltammograms were measured in a solution of tetra- $n$-butylammonium hexafluorophosphate $\left(\mathrm{Bu}_{4} \mathrm{NPF}_{6}\right.$, $0.1 \mathrm{M}$ ) in $\mathrm{N}, \mathrm{N}$-dimethylformamide (DMF) containing the sample at a scan rate of $100 \mathrm{mV} \mathrm{s}^{-1}$. Three-electrode system $\left(\mathrm{Ag} / \mathrm{Ag}^{+}\right.$, platinum wire and glassy carbon electrode as reference, counter and 
work electrode respectively) was used in the cyclic voltammetry method. The emission wavelength of white light (CXE-350) covers the region of 300 1000 nm. UV-vis absorption spectra were measured on a Shimadzu UV-2600 spectrophotometer. PL spectra were recorded on a Horiba Fluoromax-4 spectrofluorometer. PL quantum yields were measured using a Hamamatsu absolute PL quantum yield spectrometer C11347 Quantaurus_QY. Electron spin resonance (ESR) measurements were carried out on Bruker ELEXSYS-II E500 in X-band. Particle size analysis was performed on a Malvern Zetasizer Nano-S90. Transmission electron microscope image of PQ-TPAOC1 NPs was captured by Tecnai G2 F20 (FEI, America). Confocal laser scanning microscopy images were conducted using a LSM 880 confocal laser scanning microscope (ZEISS).

The ground state and excited state geometries were optimized using the density function theory (DFT) and time-dependent density functional theory (TDDFT) method, respectively, with PBE0 hybrid functional at the basis set level of 6-31G(d,p) in gas phase, performed by Gaussian 16 program package. For triplet state $\left(\mathrm{T}_{1}\right)$ geometry optimization, unrestricted DFT (UDFT) was adopted to yield the $\mathrm{T}_{1}$ structures in the same level. The vertical transition energy based on $\mathrm{S}_{0}$ geometries were calculated in PBE0/def2-TZVP level. The independent gradient model (IGM) analysis, visualization of hole and particle distribution of natural transition orbitals (NTOs), electrostatic potential (ESP) distributions and triplet state spin density distribution (TSDD) analysis were using Multiwfn and VMD softwares. The spin-orbit coupling (SOC) values were calculated using TDDFT method at the level of PBE0/def2-TZVP, performed by ORCA 4.1. Based on the obtained geometric and electronic data, the normal mode analyses for reorganization energy were performed by DUSHIN module in MOMAP.

\section{Synthesis and characterization}

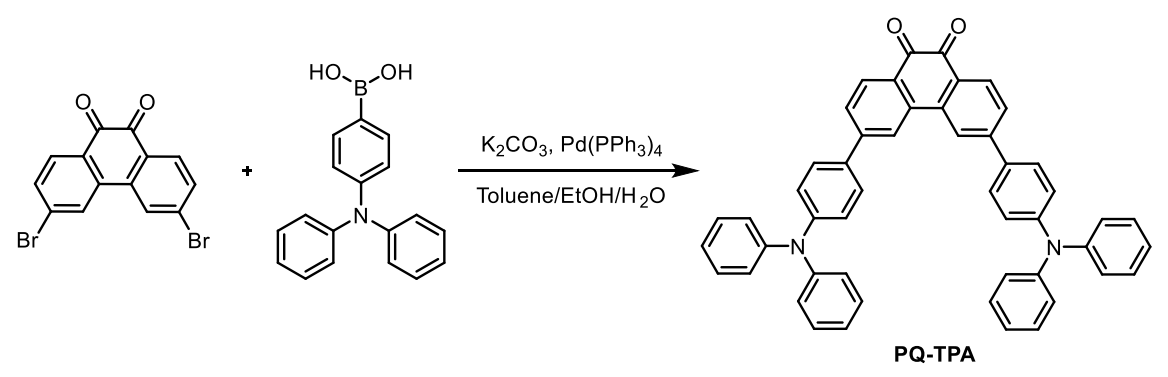

3,6-Bis(4-(diphenylamino)phenyl)phenanthrene-9,10-dione $\quad$ (PQ-TPA): A solution of

3,6-dibromophenanthrene-9,10-dione (0.73 g, 2 mmol), (4-(diphenylamino)phenyl)boronic acid (1.45 g, $5 \mathrm{mmol}), \mathrm{Pd}\left(\mathrm{PPh}_{3}\right)_{4}(0.23 \mathrm{mg}, 0.2 \mathrm{mmol})$, and potassium carbonate $(1.1 \mathrm{~g}, 8 \mathrm{mmol})$ in $50 \mathrm{~mL}$ of a degassed toluene/ethanol/water mixture $(8: 1: 1 \mathrm{v} / \mathrm{v} / \mathrm{v})$ was heated to reflux for $8 \mathrm{~h}$ under nitrogen. After 
the mixture was cooled to room temperature, the toluene layer was separated from the aqueous layer. The organic layer was washed successively with dichloromethane and dried over anhydrous $\mathrm{Na}_{2} \mathrm{SO}_{4}$. Then, the solvent was evaporated under reduced pressure. The residue was purified by silica-gel column chromatography and then recrystallization. PQ-TPA was obtained as a deep-red solid in $47.5 \%$ yield. ${ }^{1} \mathrm{H}$ NMR (500 MHz, $\left.\mathrm{CDCl}_{3}, \delta\right): 8.29-8.20(\mathrm{~m}, 4 \mathrm{H}), 7.68-7.63(\mathrm{~m}, 2 \mathrm{H}), 7.61-7.55(\mathrm{~m}, 4 \mathrm{H}), 7.34-7.28(\mathrm{~m}$, 8H), 7.20-7.14 (m, 12H), 7.13-7.07 (m, 4H). ${ }^{13} \mathrm{C} \mathrm{NMR} \mathrm{(125} \mathrm{MHz,} \mathrm{CDCl}_{3}, \delta$ ): 180.05, 149.00, 148.11, $147.17,136.24,132.30,131.26,129.49,129.43,128.08,127.46,125.10,123.77,122.79,121.71$ HRMS: $m / z\left[\mathrm{M}+\mathrm{H}^{+}\right]$found, $695.2679\left(\mathrm{C}_{50} \mathrm{H}_{34} \mathrm{~N}_{2} \mathrm{O}_{2}\right.$, calcd., 694.2620).

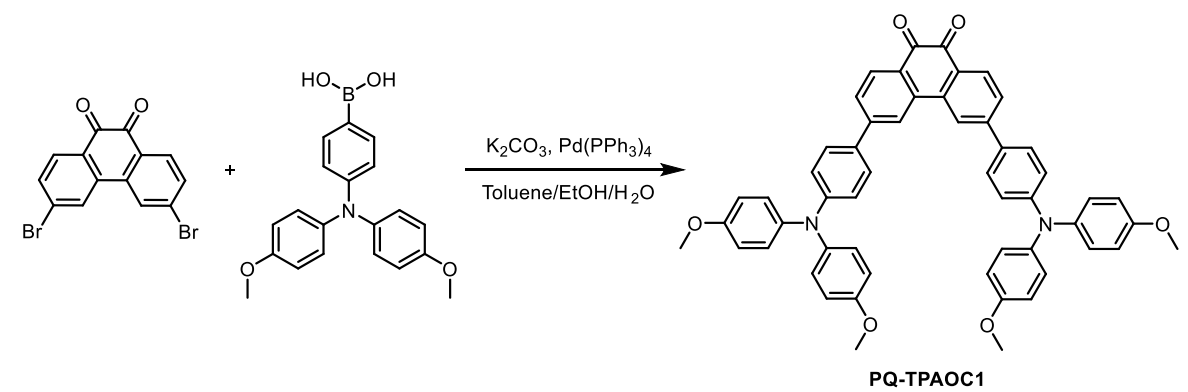

3,6-Bis(4-(bis(4-methoxyphenyl)amino)phenyl)phenanthrene-9,10-dione (PQ-TPAOC1): The procedure was analogous to that described for PQ-TPA. Deep violet solid, yield $49.7 \%$. ${ }^{1} \mathrm{H}$ NMR $(500$ $\left.\mathrm{MHz}, \mathrm{CDCl}_{3}, \delta\right): 8.26-8.16(\mathrm{~m}, 4 \mathrm{H}), 7.65-7.58(\mathrm{~m}, 2 \mathrm{H}), 7.57-7.48(\mathrm{~m}, 4 \mathrm{H}), 7.20-6.94(\mathrm{~m}, 12 \mathrm{H})$, 6.93-6.83 (m, 8H), 3.83 (s, 12H). ${ }^{13} \mathrm{C}$ NMR (125 MHz, $\left.\mathrm{CDCl}_{3}, \delta\right): 180.07,156.57,148.16,136.27$, $131.21,129.19,127.82,127.31,127.25,127.12,121.45,121.40,119.75,114.85,55.53$. HRMS: $\mathrm{m} / z$ [M $\left.+\mathrm{H}^{+}\right]$found, $815.3097\left(\mathrm{C}_{54} \mathrm{H}_{42} \mathrm{~N}_{2} \mathrm{O}_{6}\right.$, calcd., 814.3043).

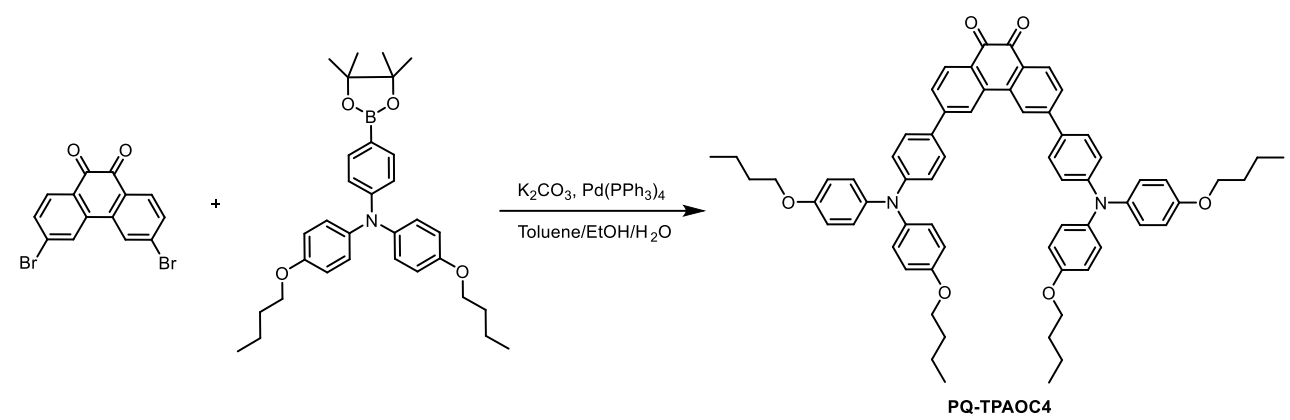

3,6-Bis(4-(bis(4-butoxyphenyl)amino)phenyl)phenanthrene-9,10-dione (PQ-TPAOC4): The procedure was analogous to that described for PQ-TPA. Deep violet solid, yield 42.8\%. ${ }^{1} \mathrm{H}$ NMR (500 $\left.\mathrm{MHz}, \mathrm{CDCl}_{3}, \delta\right): 8.26-8.13(\mathrm{~m}, 4 \mathrm{H}), 7.67-7.45(\mathrm{~m}, 6 \mathrm{H}), 7.25-6.72(\mathrm{~m}, 20 \mathrm{H}), 4.18-3.76(\mathrm{br}, 8 \mathrm{H})$, $1.86-1.71(\mathrm{~m}, 8 \mathrm{H}), 1.56-1.46(\mathrm{~m}, 8 \mathrm{H}), 0.99(\mathrm{t}, J=7.4 \mathrm{~Hz}, 12 \mathrm{H}) .{ }^{13} \mathrm{C} \mathrm{NMR}\left(125 \mathrm{MHz}, \mathrm{CDCl}_{3}, \delta\right)$ : 180.06, 156.16, 148.19, 139.72, 136.26, 131.18, 130.25, 129.13, 127.82, 127.24, 127.09, 121.34, 119.54, 
115.38, 67.94, 31.40, 19.28, 13.88. HRMS: $m / z\left[\mathrm{M}+\mathrm{H}^{+}\right]$found, $983.4970\left(\mathrm{C}_{66} \mathrm{H}_{66} \mathrm{~N}_{2} \mathrm{O}_{6}\right.$, calcd., 982.4921).

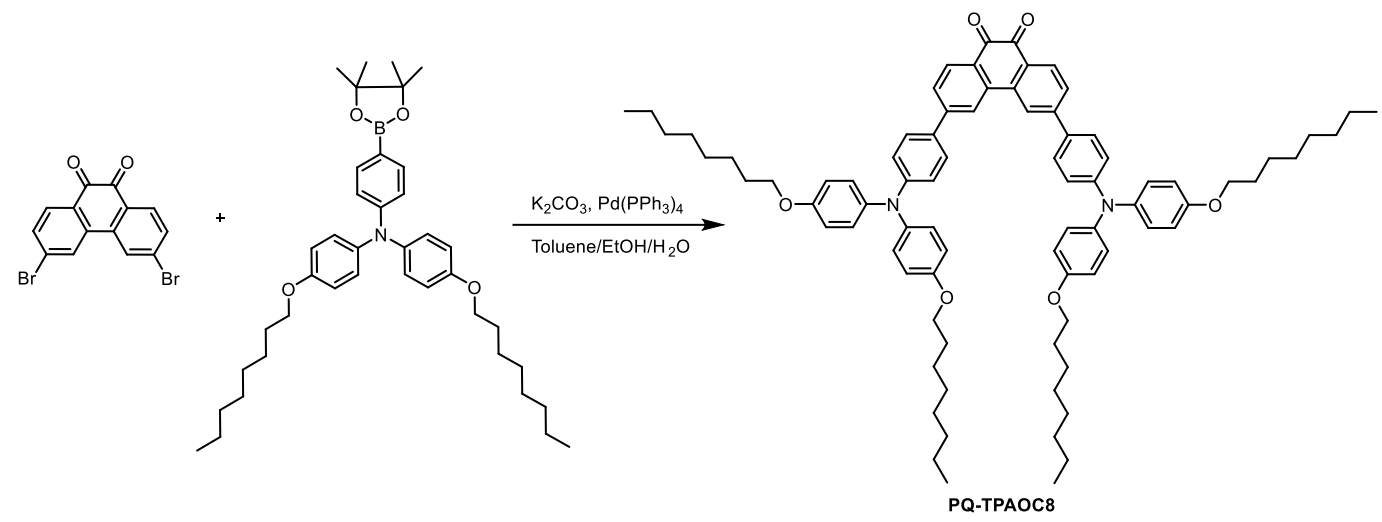

3,6-Bis(4-(bis(4-(octyloxy)phenyl)amino)phenyl)phenanthrene-9,10-dione (PQ-TPAOC8): The procedure was analogous to that described for PQ-TPA. Deep violet solid, yield $30.7 \%$. ${ }^{1} \mathrm{H}$ NMR (400 $\left.\mathrm{MHz}, \mathrm{CDCl}_{3}, \delta\right):$ 8.26-8.14 (m, 4H), 7.66-7.58 (m, 2H), 7.57-7.46 (m, 4H), 7.18-7.05 (m, 8H), 7.04-6.95 (m, 4H), 6.94-6.81 (m, 8H), 4.06-3.86 (m, 8H), 1.88-1.72 (m, 8H), 1.53-1.23 (m, 40H), 0.96-0.81 (m, 12H). ${ }^{13} \mathrm{C}$ NMR (100 MHz, $\left.\mathrm{CDCl}_{3}, \delta\right): 180.10,156.10,148.28,139.93,136.30,131.21$, $129.15,127.87,127.34,127.27,127.20,127.14,121.37,119.62,119.56,115.43,68.30,31.85,29.41$, 29.37, 29.28, 26.12, 22.69, 14.13. HRMS: $m / z\left[\mathrm{M}+\mathrm{H}^{+}\right]$found, $1207.7468\left(\mathrm{C}_{82} \mathrm{H}_{98} \mathrm{~N}_{2} \mathrm{O}_{6}\right.$, calcd., 1206.7425).

\section{X-ray crystallography}

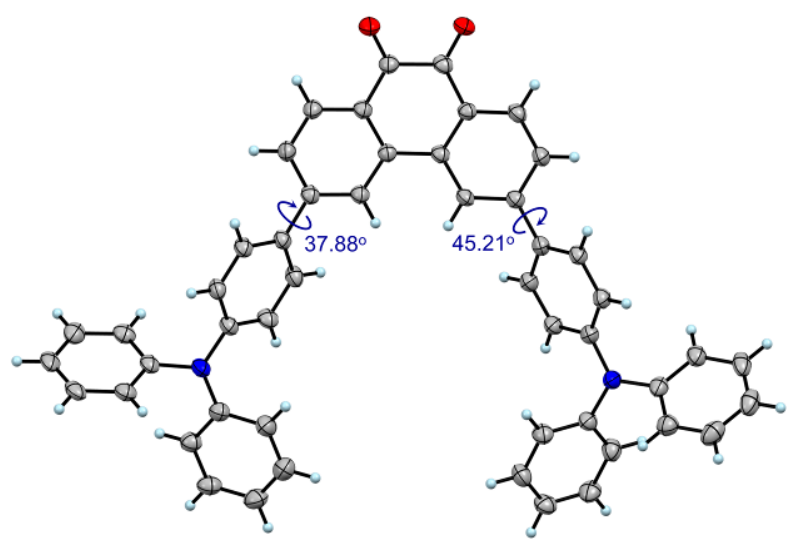

Crystal data for PQ-TPA (CCDC 2087038): $\mathrm{C}_{50} \mathrm{H}_{34} \mathrm{~N}_{2} \mathrm{O}_{2}, M_{\mathrm{W}}=694.79$, monoclinic, $P 2_{1} / c, a=$ 17.9667(6), $b=9.60705(19), c=21.6302(6) \AA, \alpha=90^{\circ}, \beta=105.709(3)^{\circ}, \gamma=90^{\circ}, V=3594.07(18) \AA^{3}$, $\mathrm{Z}=4, D \mathrm{c}=1.284 \mathrm{~g} \mathrm{~cm}^{-3}, \mu=0.609 \mathrm{~mm}^{-1}, F(000)=1456.0, T=149.99(10) \mathrm{K}, R_{1}(\mathrm{I}>2 \sigma(\mathrm{I}))=0.0551$, $\mathrm{w} R_{2}(\mathrm{I}>2 \sigma(\mathrm{I}))=0.1386, R_{1}($ all data $)=0.0766, \mathrm{w} R_{2}($ all data $)=0.1499$. 


\section{Supporting figures}

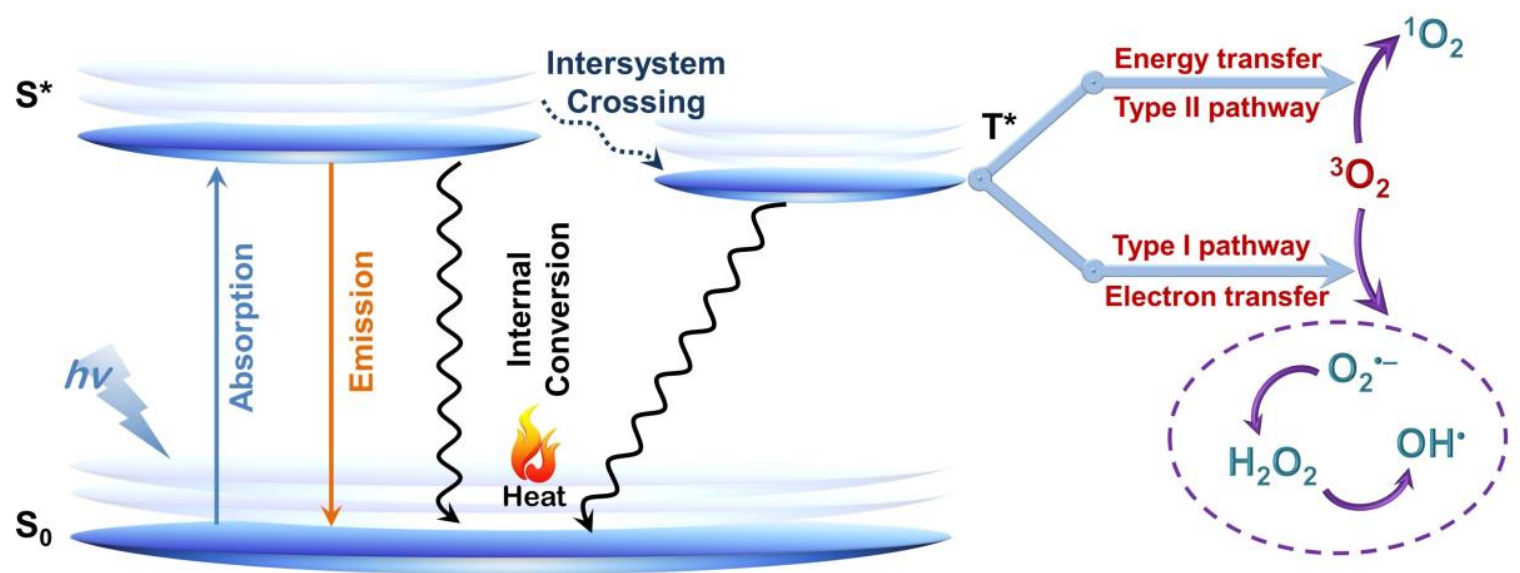

Scheme S1. Schematic illustration of photophysical and photochemical mechanisms.

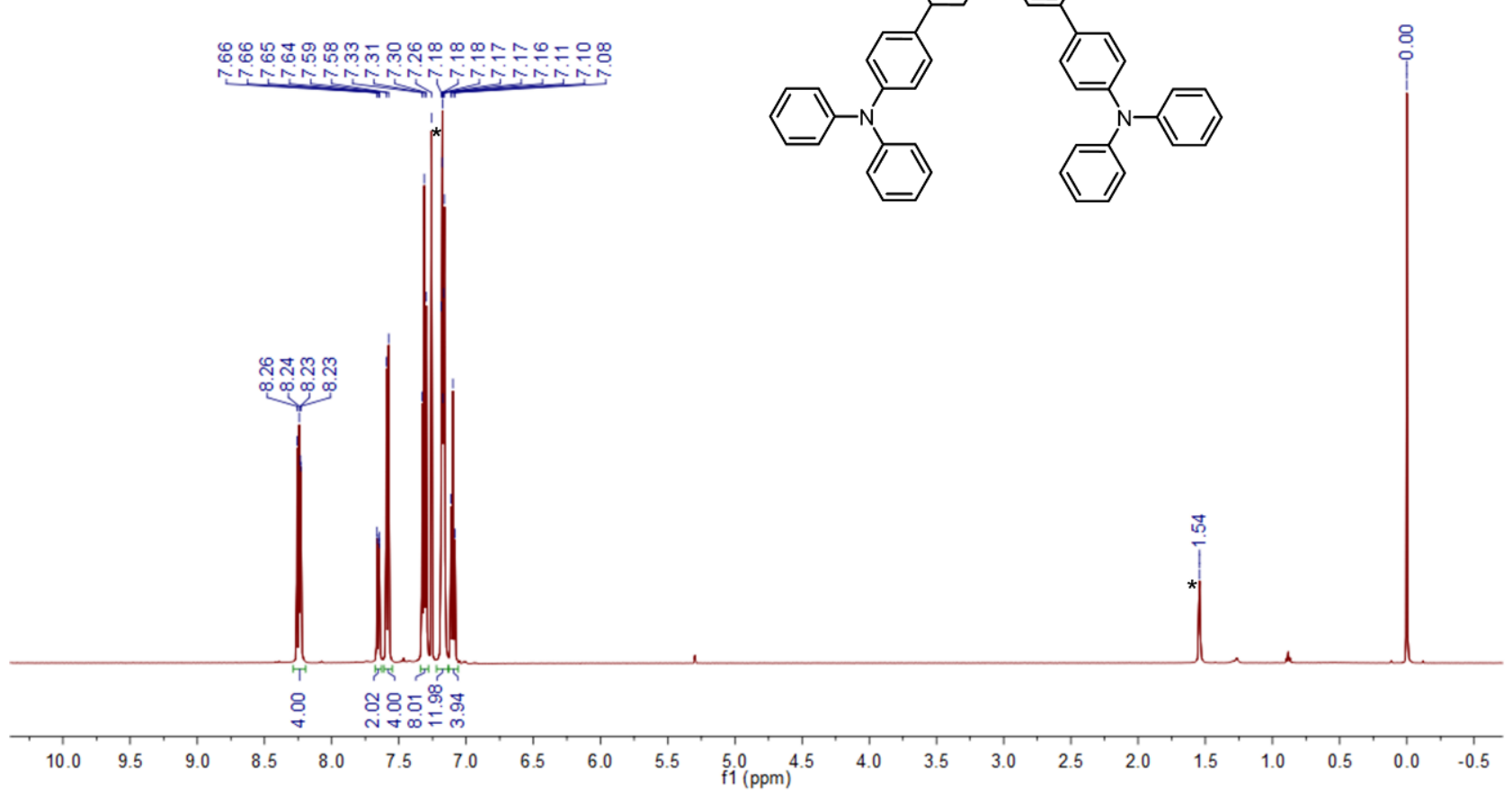

Figure S1. ${ }^{1} \mathrm{H}$ NMR spectrum of PQ-TPA in $\mathrm{CDCl}_{3}$. 


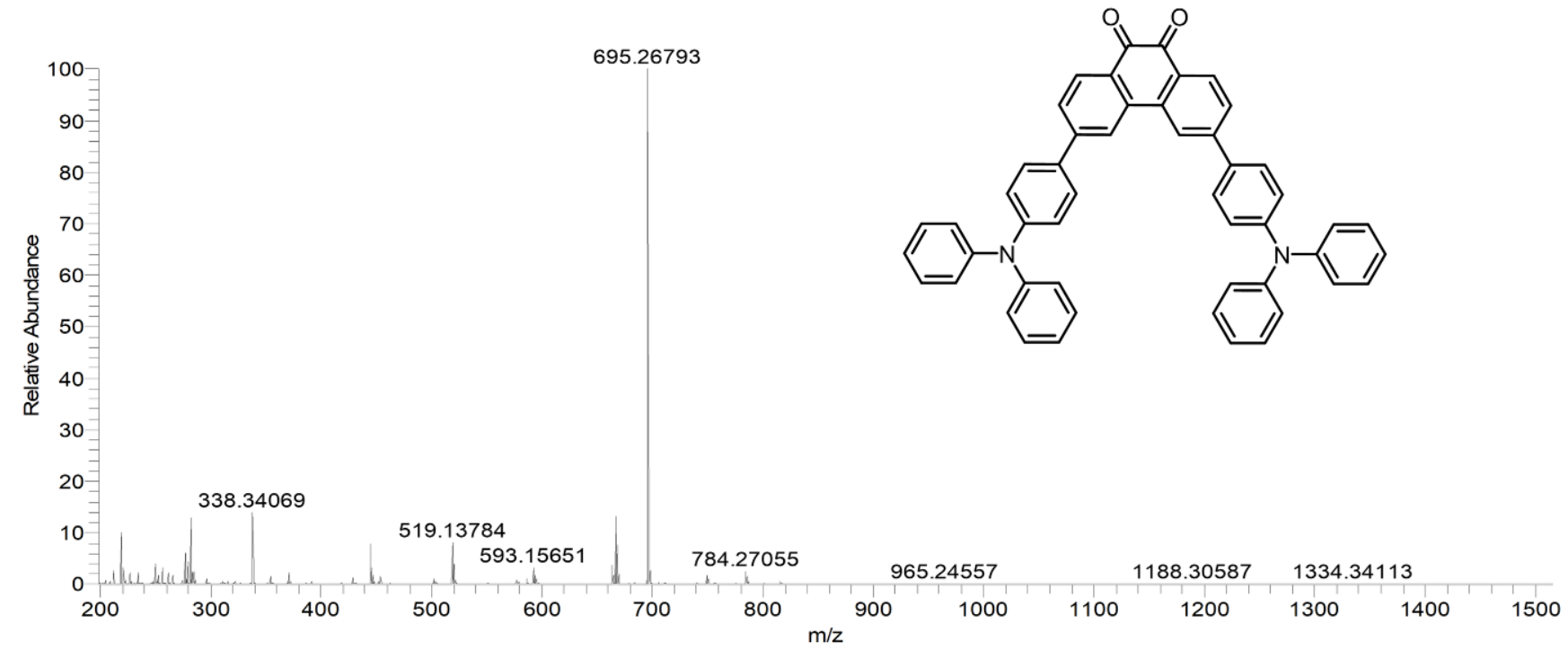

Figure S2. HRMS spectrum of PQ-TPA.

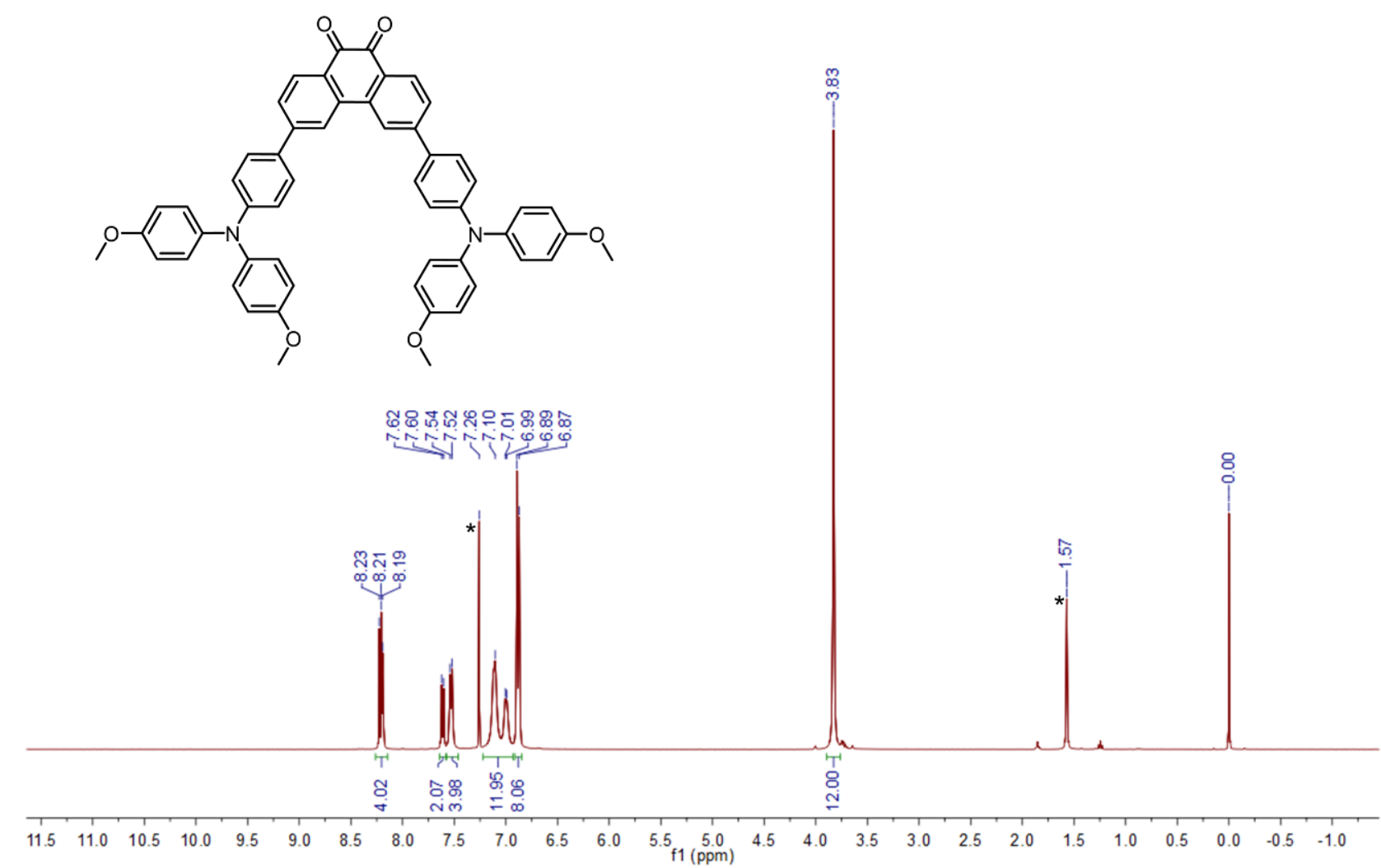

Figure S3. ${ }^{1} \mathrm{H}$ NMR spectrum of PQ-TPAOC1 in $\mathrm{CDCl}_{3}$. 


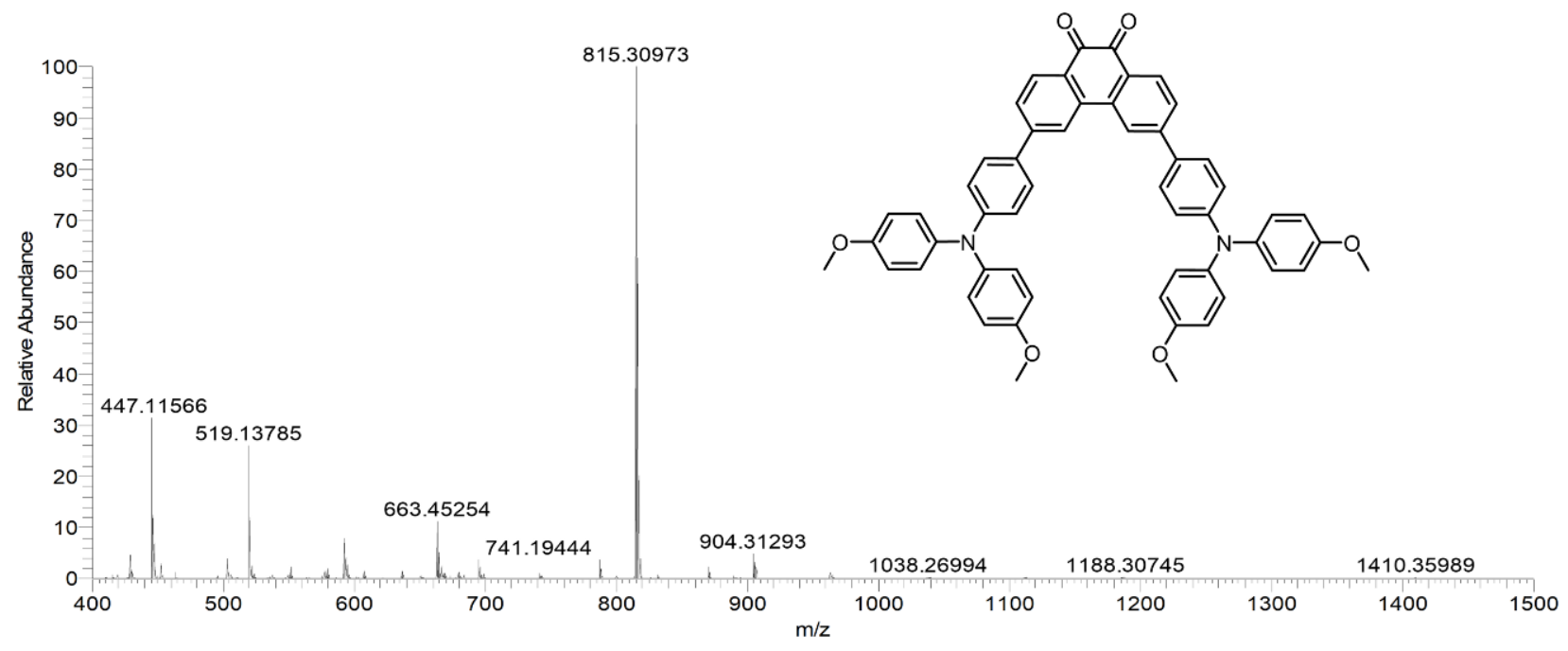

Figure S4. HRMS spectrum of PQ-TPAOC1.

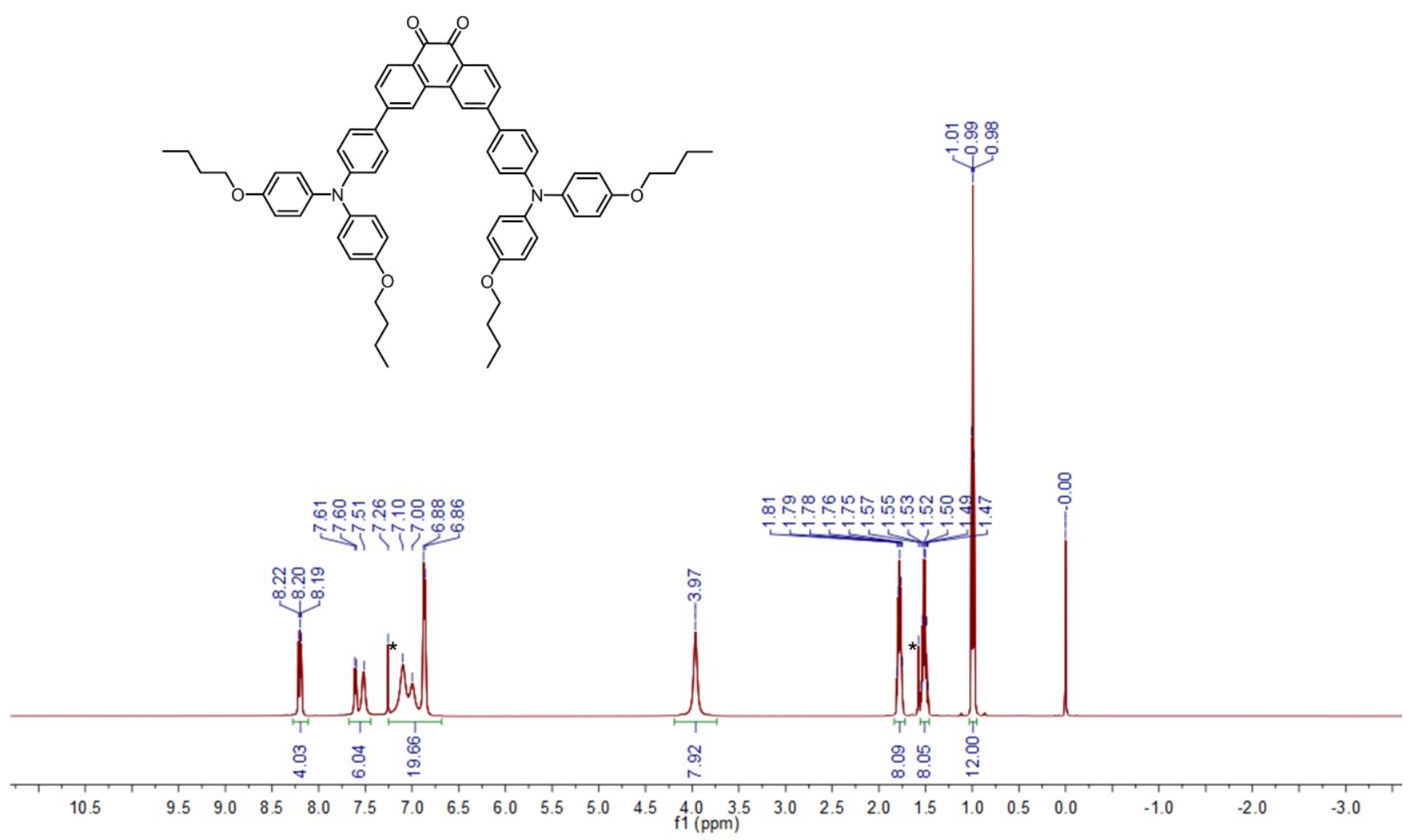

Figure S5. ${ }^{1} \mathrm{H}$ NMR spectrum of PQ-TPAOC4 in $\mathrm{CDCl}_{3}$. 


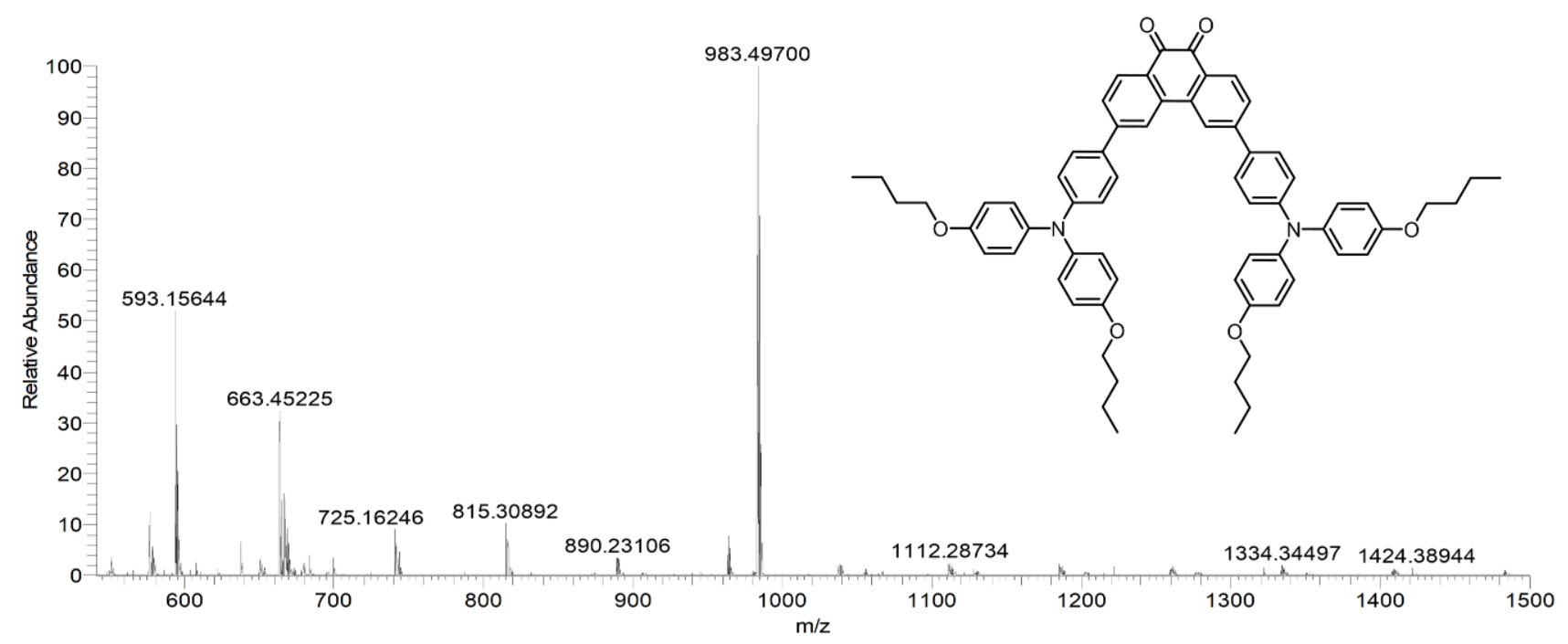

Figure S6. HRMS spectrum of PQ-TPAOC4.

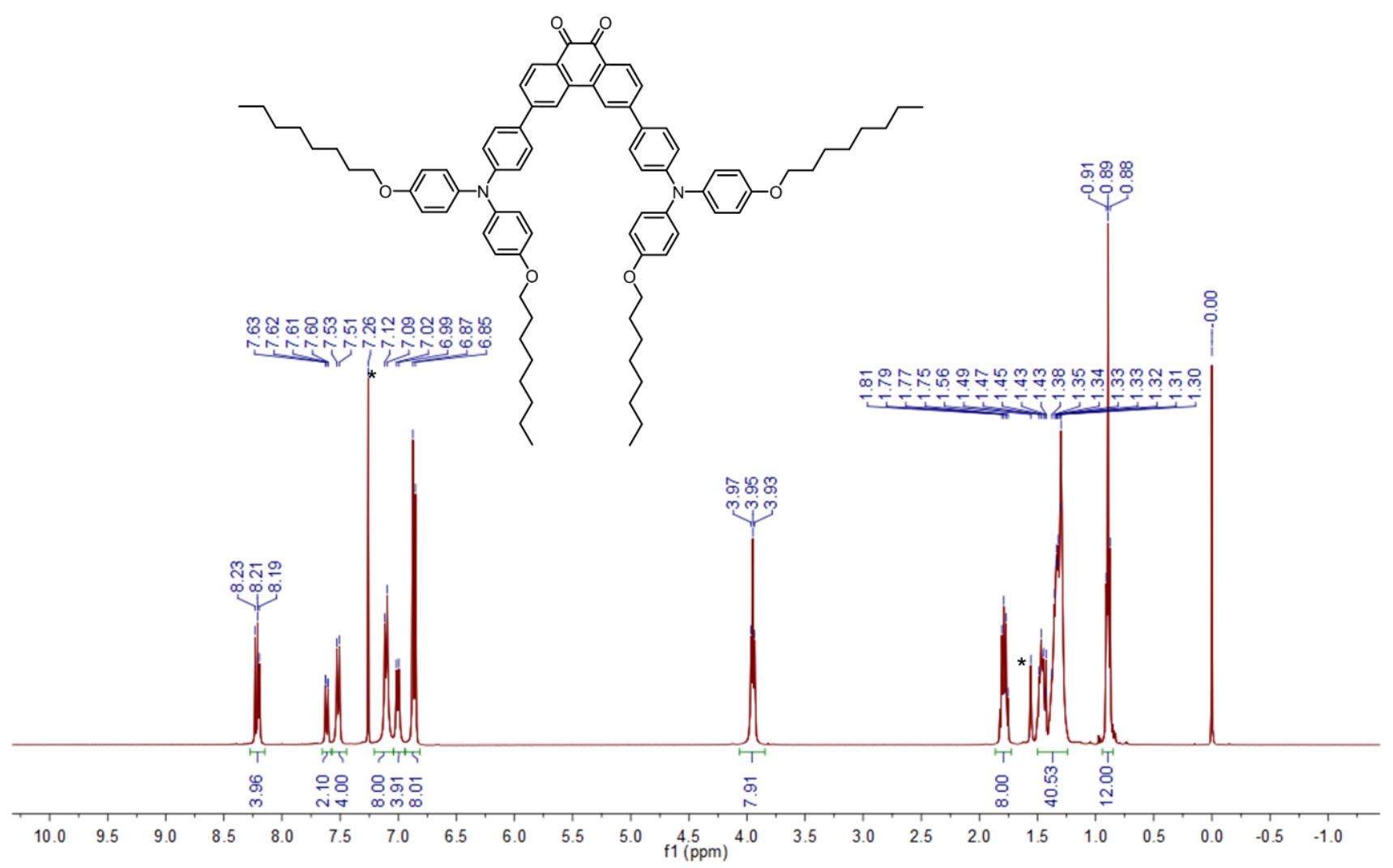

Figure S7. ${ }^{1} \mathrm{H}$ NMR spectrum of PQ-TPAOC8 in $\mathrm{CDCl}_{3}$. 


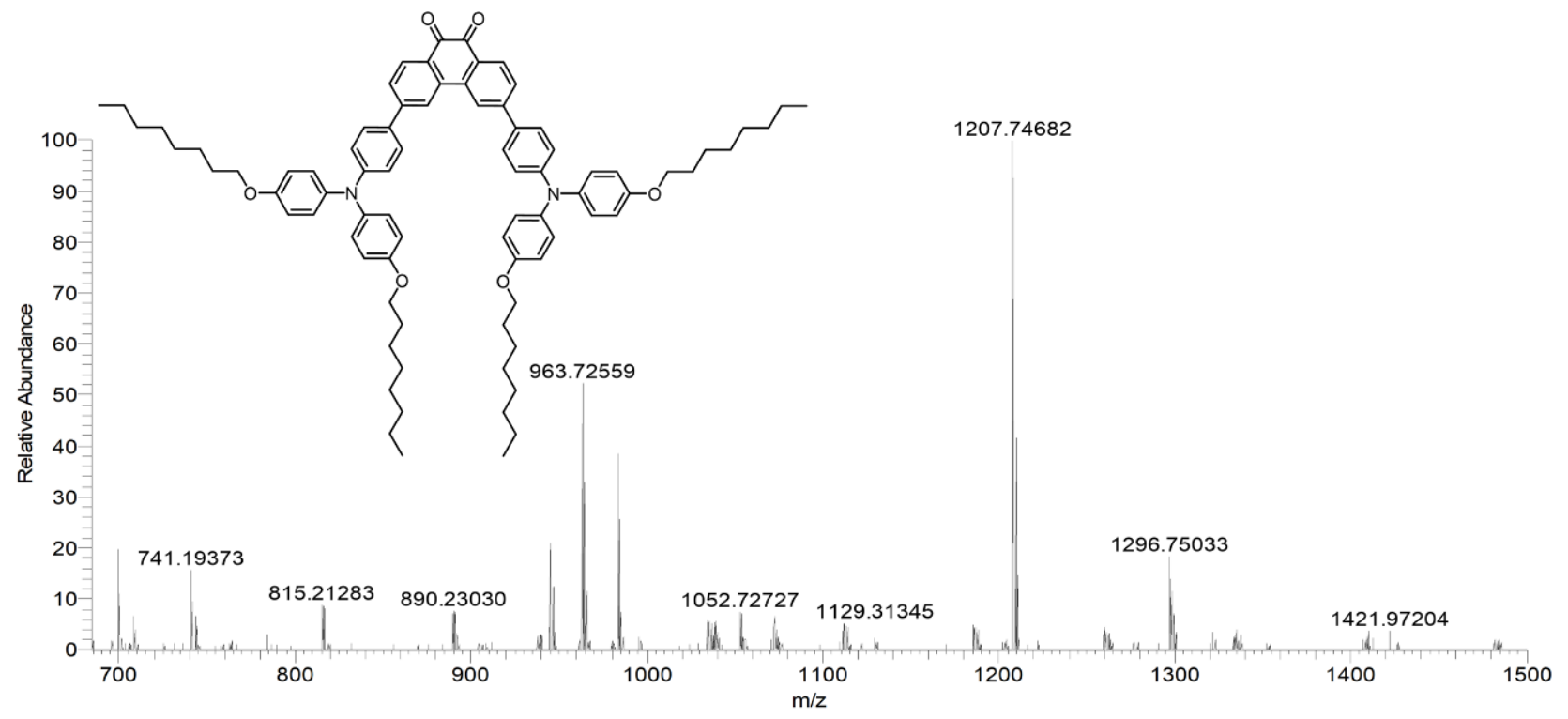

Figure S8. HRMS spectrum of PQ-TPAOC8.

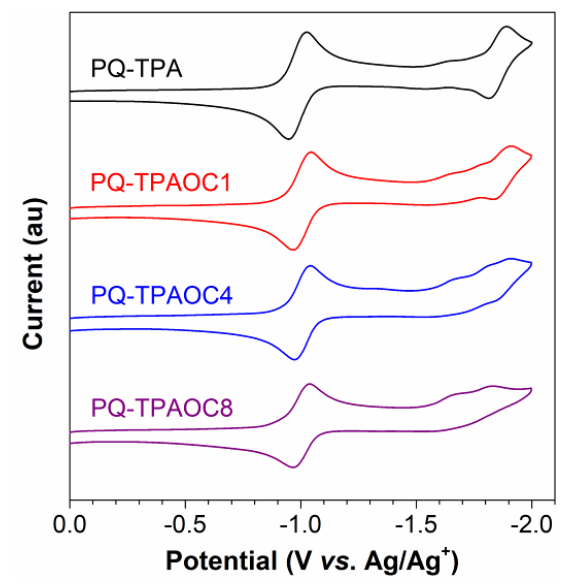

Figure S9. Cyclic voltammograms of PQ-TPA, PQ-TPAOC1, PQ-TPAOC4 and PQ-TPAOC8, measured in $N, N$-dimethylformamide containing $0.1 \mathrm{M}$ tetra- $n$-butylammonium hexafluorophosphate. Scan rate: $100 \mathrm{mV} \mathrm{s}^{-1}$.

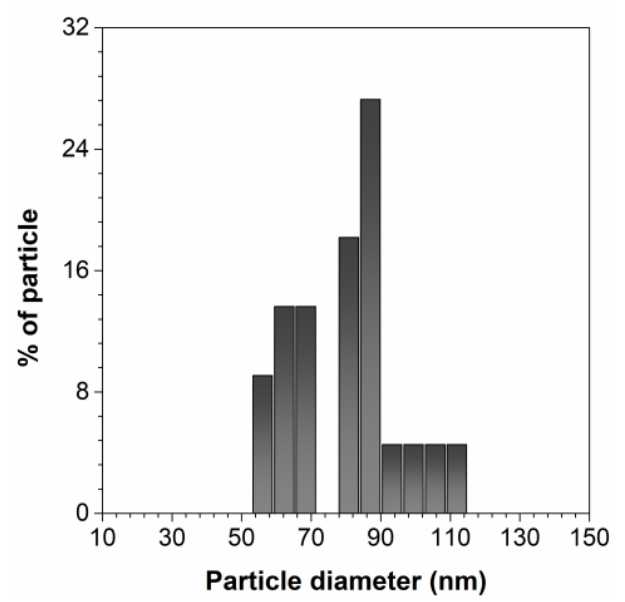

Figure S10. The size distribution histogram of PQ-TPAOC1 NPs obtained from the TEM image. 



Figure S11. DLS profile of the (A) PQ-TPA NPs, (B) PQ-TPAOC4 NPs and (C) PQ-TPAOC8 NPs. Inset: the average hydrodynamic diameter $\left(D_{\mathrm{h}}\right)$ and PDI of NPs measured by DLS; the photographs of NPs taken under room light.

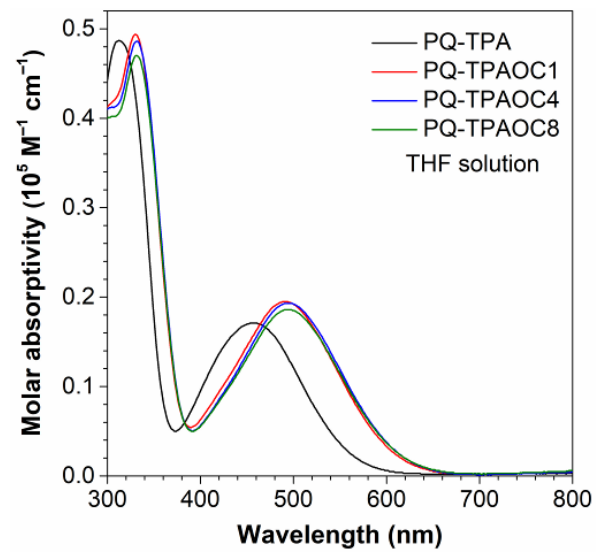

Figure S12. UV-vis absorption spectra of PQ-TPA, PQ-TPAOC1, PQ-TPAOC4 and PQ-TPAOC8 in THF solutions $\left(10^{-5} \mathrm{M}\right)$. 

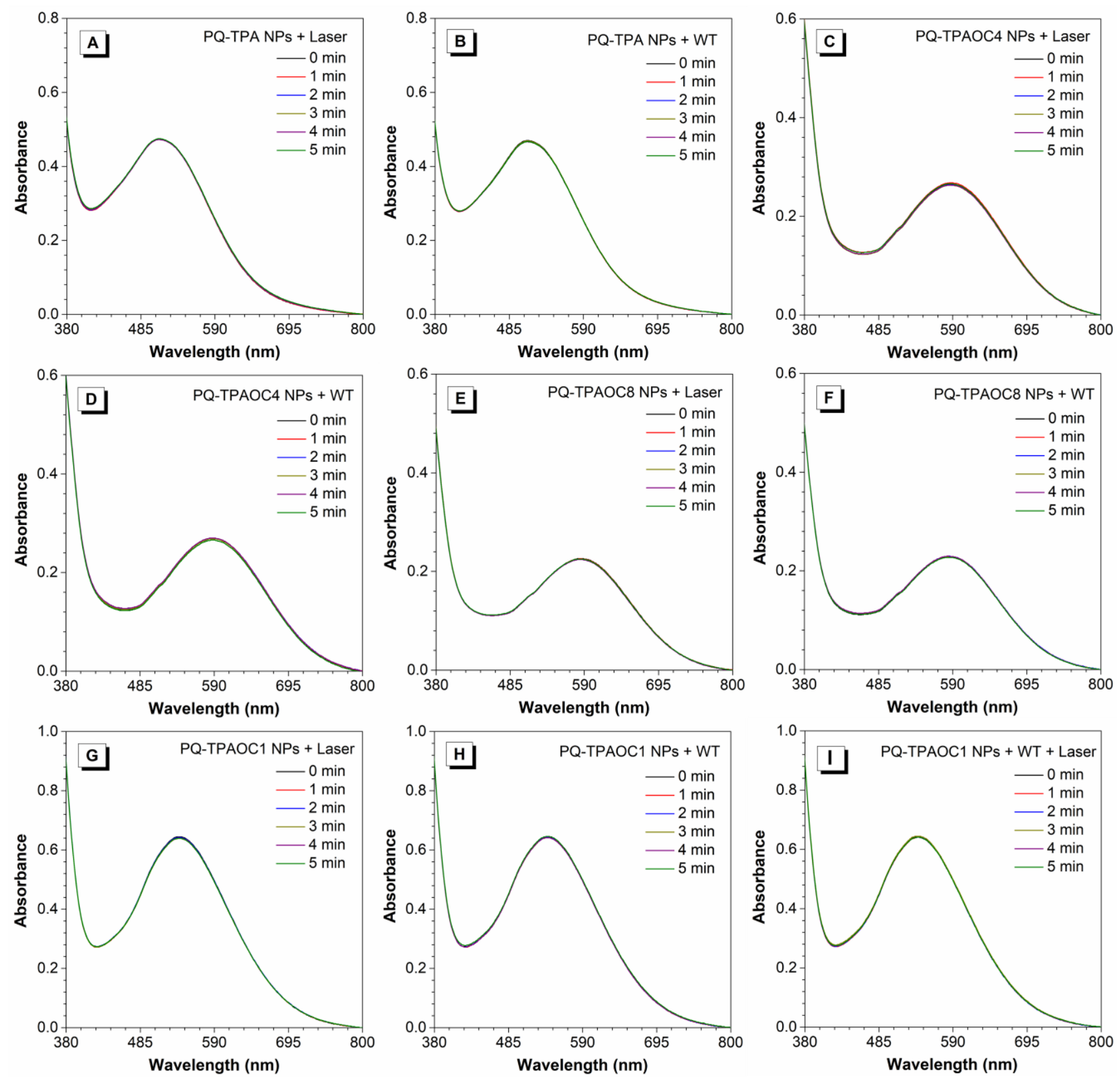

Figure S13. UV-vis absorption spectra of PQ-TPA NPs, PQ-TPAOC1 NPs, PQ-TPAOC4 NPs and PQ-TPAOC8 NPs in water irradiated by $660 \mathrm{~nm}$ laser irradiation $\left(800 \mathrm{~mW} \mathrm{~cm}^{-2}\right)$ and/or white light $\left(200 \mathrm{~mW} \mathrm{~cm}^{-2}\right)$ for $0,1,2,3,4$, and $5 \mathrm{~min}$, respectively. 

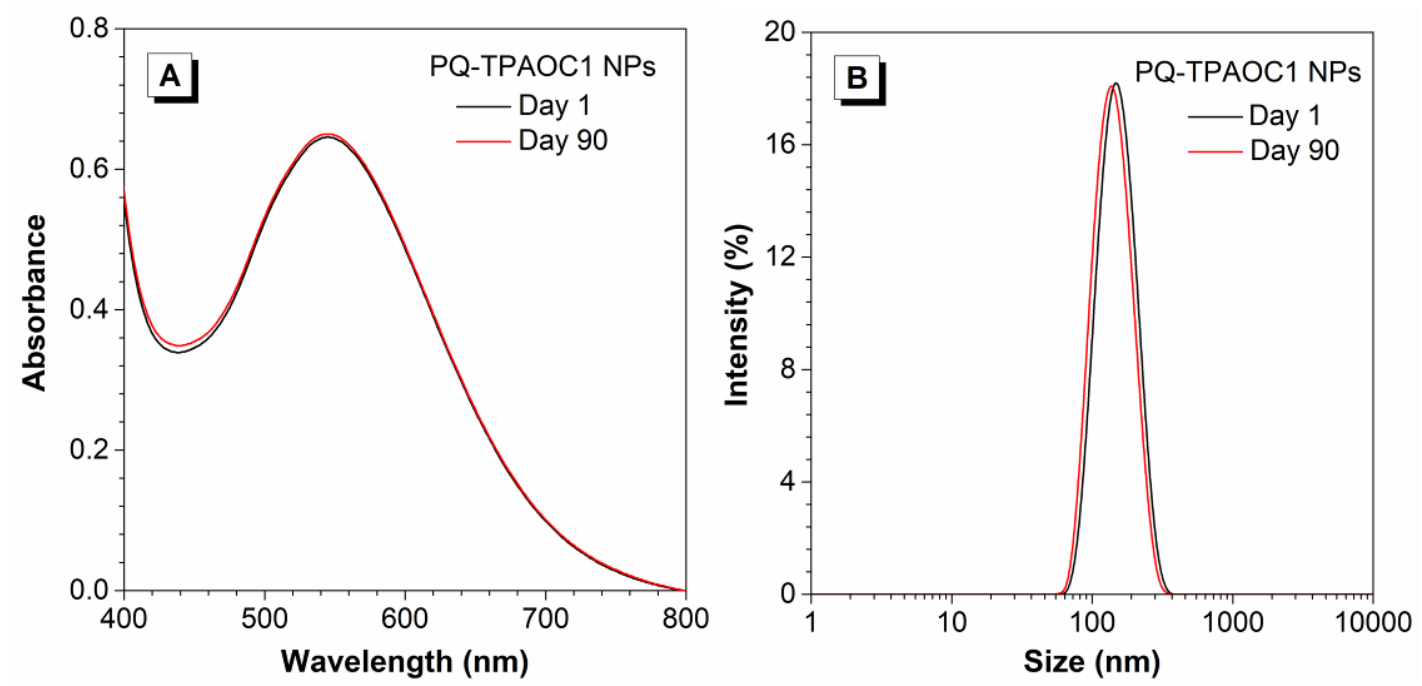

Figure S14. (A) UV-vis absorption spectra and (B) the DLS analysis results of PQ-TPAOC1 NPs at Day 1 and Day 90 (stored at $4{ }^{\circ} \mathrm{C}$ ).

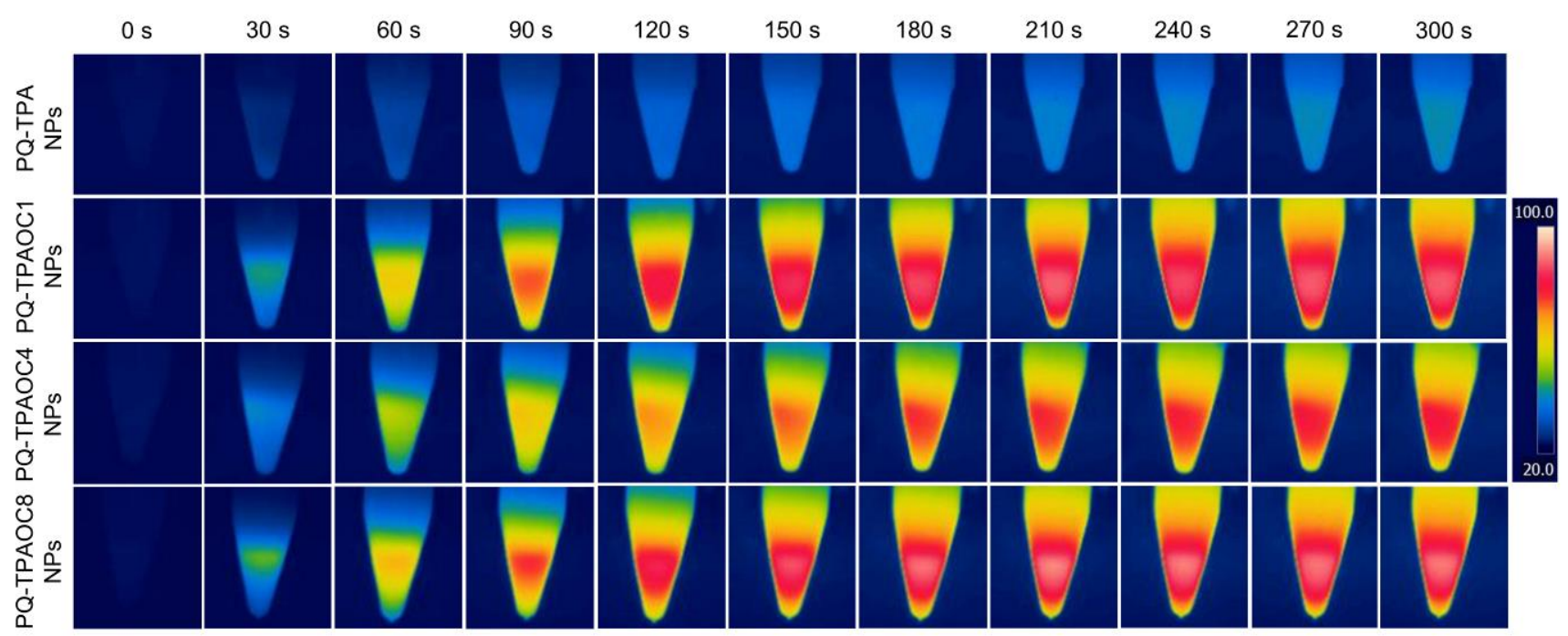

Figure S15. IR thermal images of PQ-TPA NPs, PQ-TPAOC1 NPs, PQ-TPAOC4 NPs and PQ-TPAOC8 NPs in aqueous solution $(150 \mu \mathrm{M})$ upon exposure to $660 \mathrm{~nm}\left(800 \mathrm{~mW} \mathrm{~cm}^{-2}\right)$ laser irradiation for different times. 

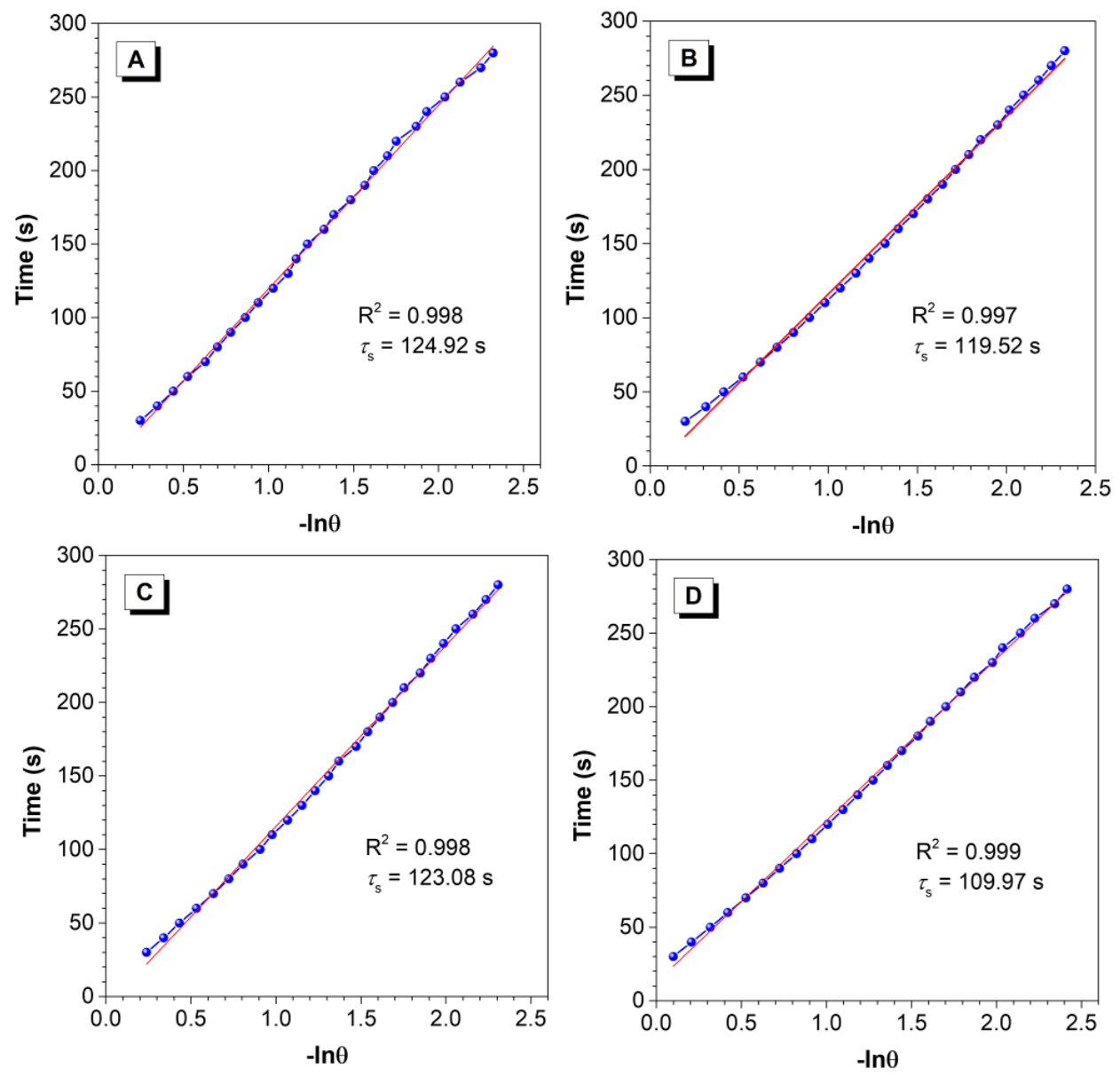

Figure S16. The linear fitting of time from the cooling period versus negative natural logarithm of driving force temperature for (A) PQ-TPA NPs, (B) PQ-TPAOC1 NPs, (C) PQ-TPAOC4 NPs and (D) PQ-TPAOC8 NPs.
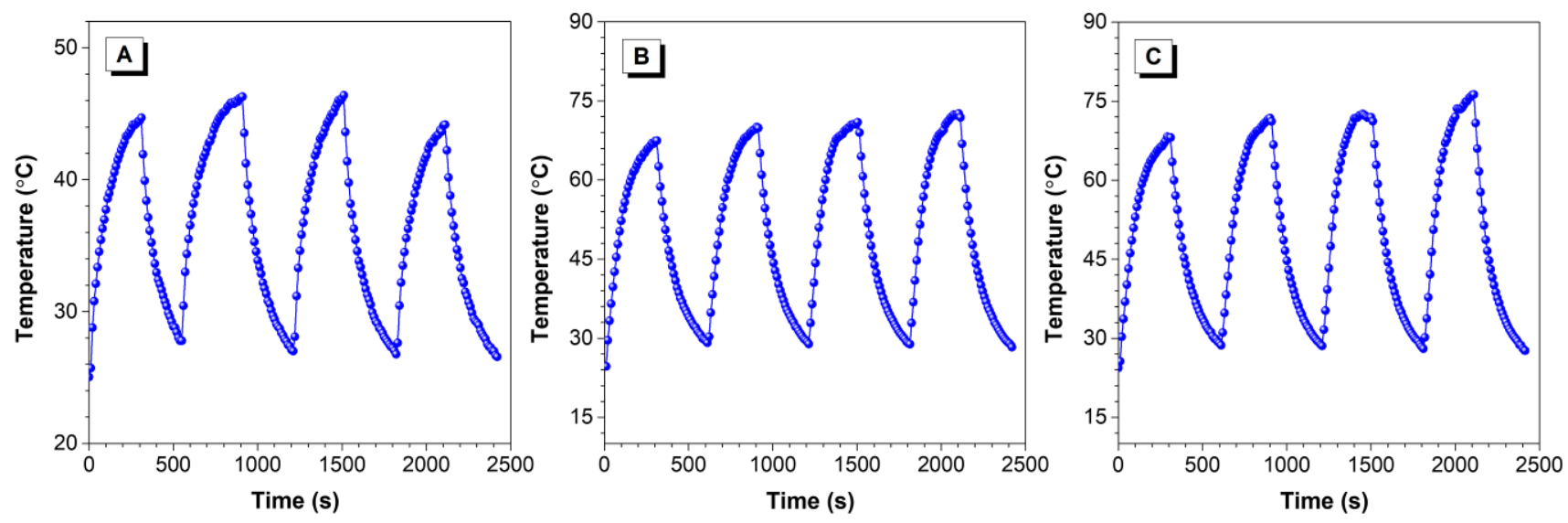

Figure S17. Photothermal curves of (A) PQ-TPA NPs, (B) PQ-TPAOC4 NPs and (C) PQ-TPAOC8 NPs subjected to four $660 \mathrm{~nm}$ laser irradiation on/off cycles at $800 \mathrm{~mW} \mathrm{~cm}^{-2}$. 

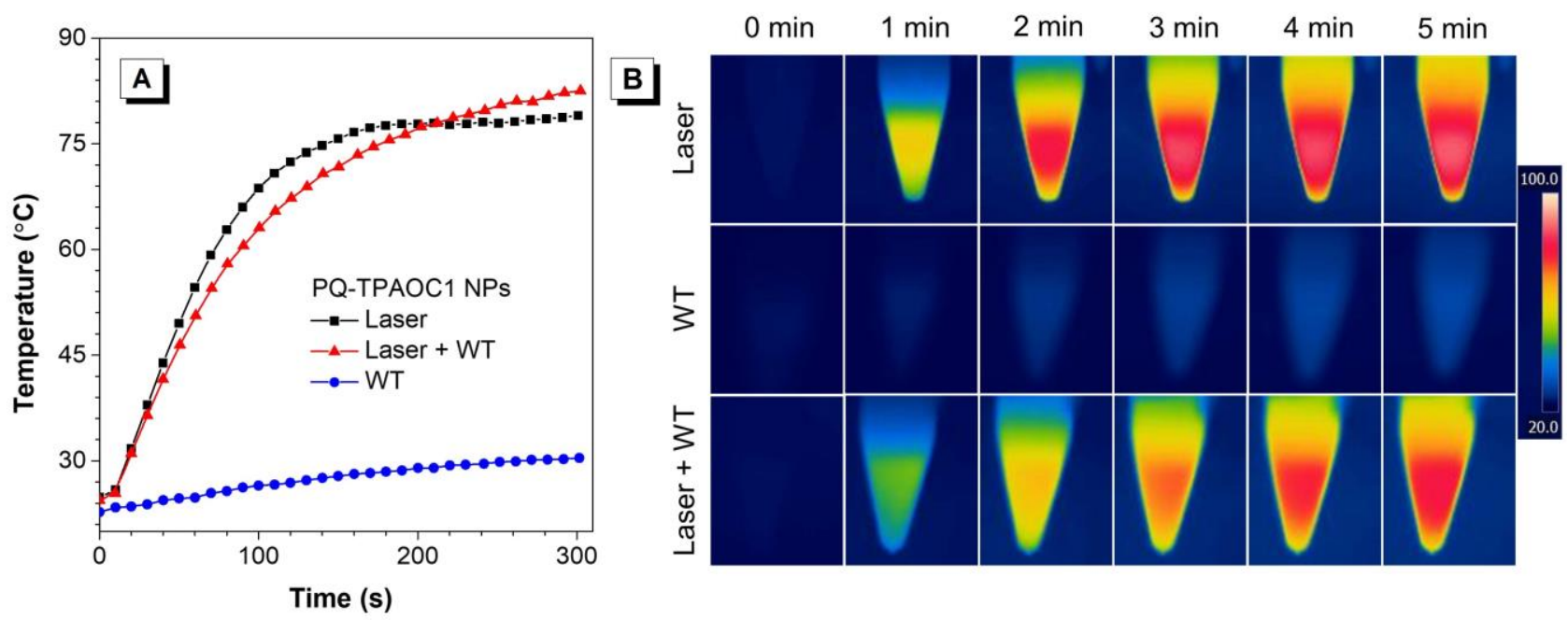

Figure S18. (A) Photothermal curves and (B) IR thermal images of PQ-TPAOC1 NPs in aqueous solution $(150 \mu \mathrm{M})$ upon white light irradiation $\left(200 \mathrm{~mW} \mathrm{~cm}^{-2}\right)$ and/or $660 \mathrm{~nm}$ laser irradiation (800 $\mathrm{mW}$ $\mathrm{cm}^{-2}$ ) for different time.
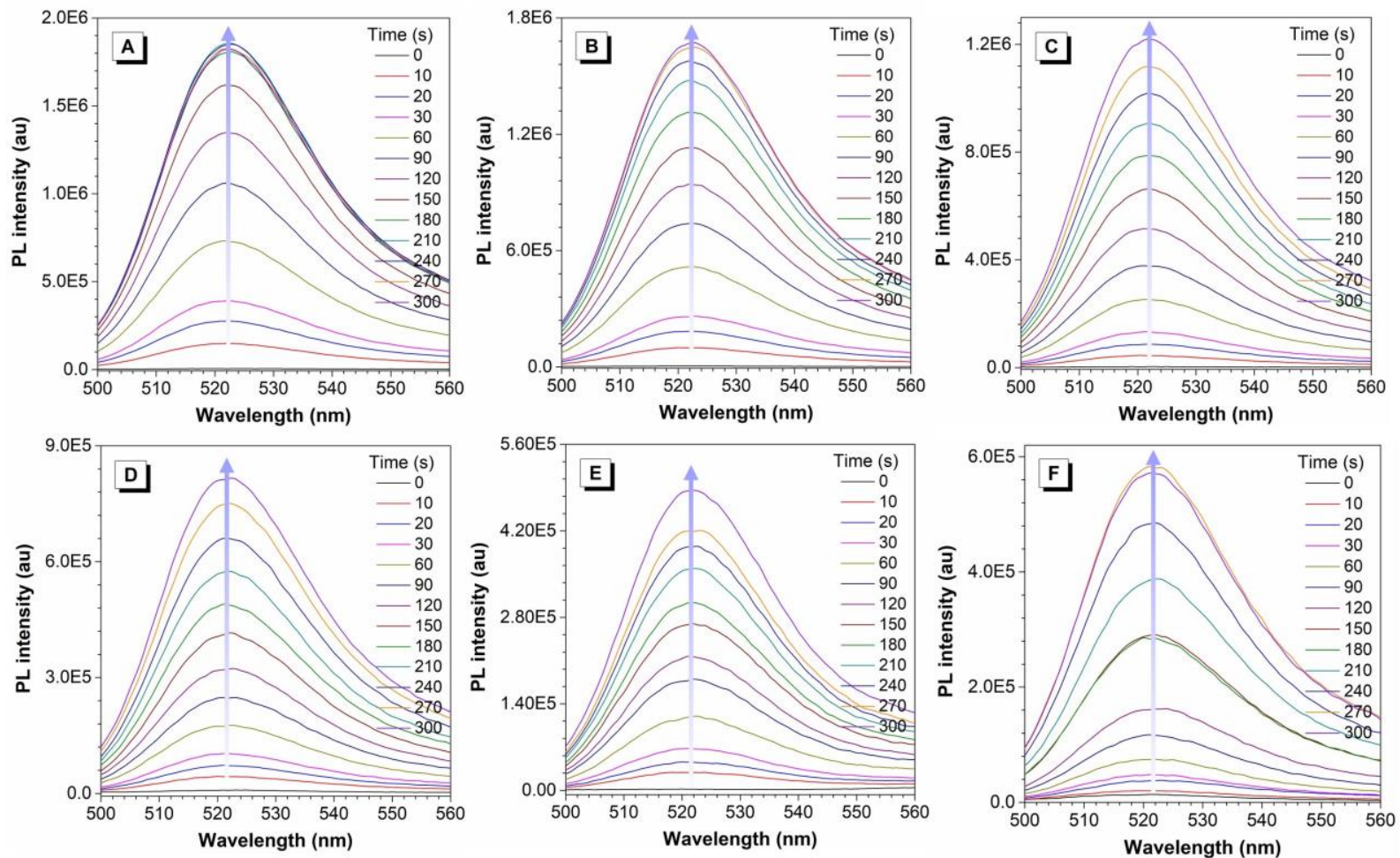

Figure S19. PL spectra of DCFH $(1 \mu \mathrm{M})$ in the presence of $1 \mu \mathrm{M}$ (A) PQ-TPA NPs, (B) PQ-TPAOC1 NPs, (C) PQ-TPAOC4 NPs, (D) PQ-TPAOC8 NPs, (E) RB NPs and (F) CV NPs in PBS, upon white

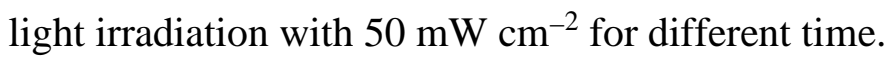



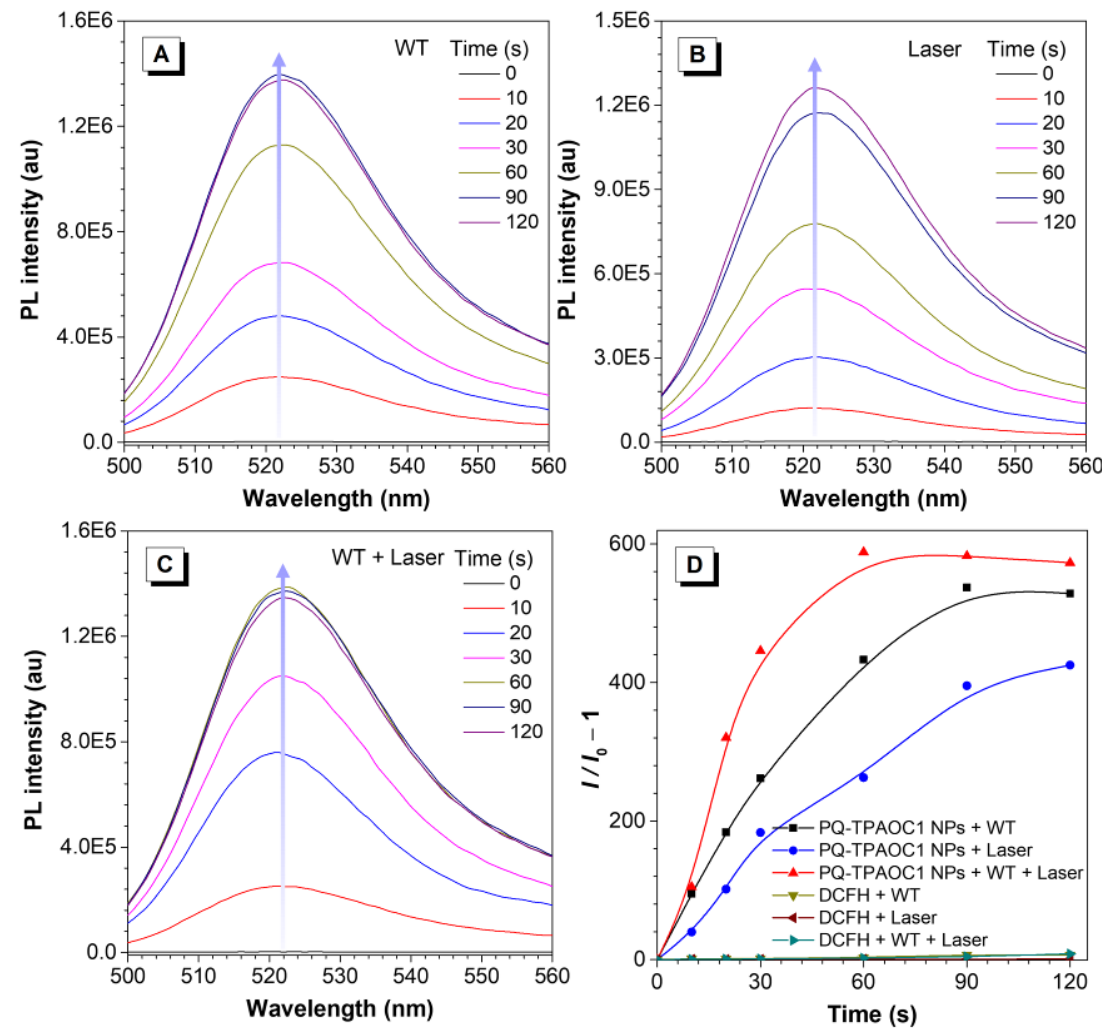

Figure S20. (A-C) PL spectra of DCFH $(1 \mu \mathrm{M})$ and (D) plots of relative PL intensity of DCFH in the presence of $1 \mu \mathrm{M}$ PQ-TPAOC1 NPs in PBS upon white light irradiation $\left(200 \mathrm{~mW} \mathrm{~cm}^{-2}\right)$ and/or $660 \mathrm{~nm}$ laser irradiation $\left(800 \mathrm{~mW} \mathrm{~cm}^{-2}\right)$ for different time.
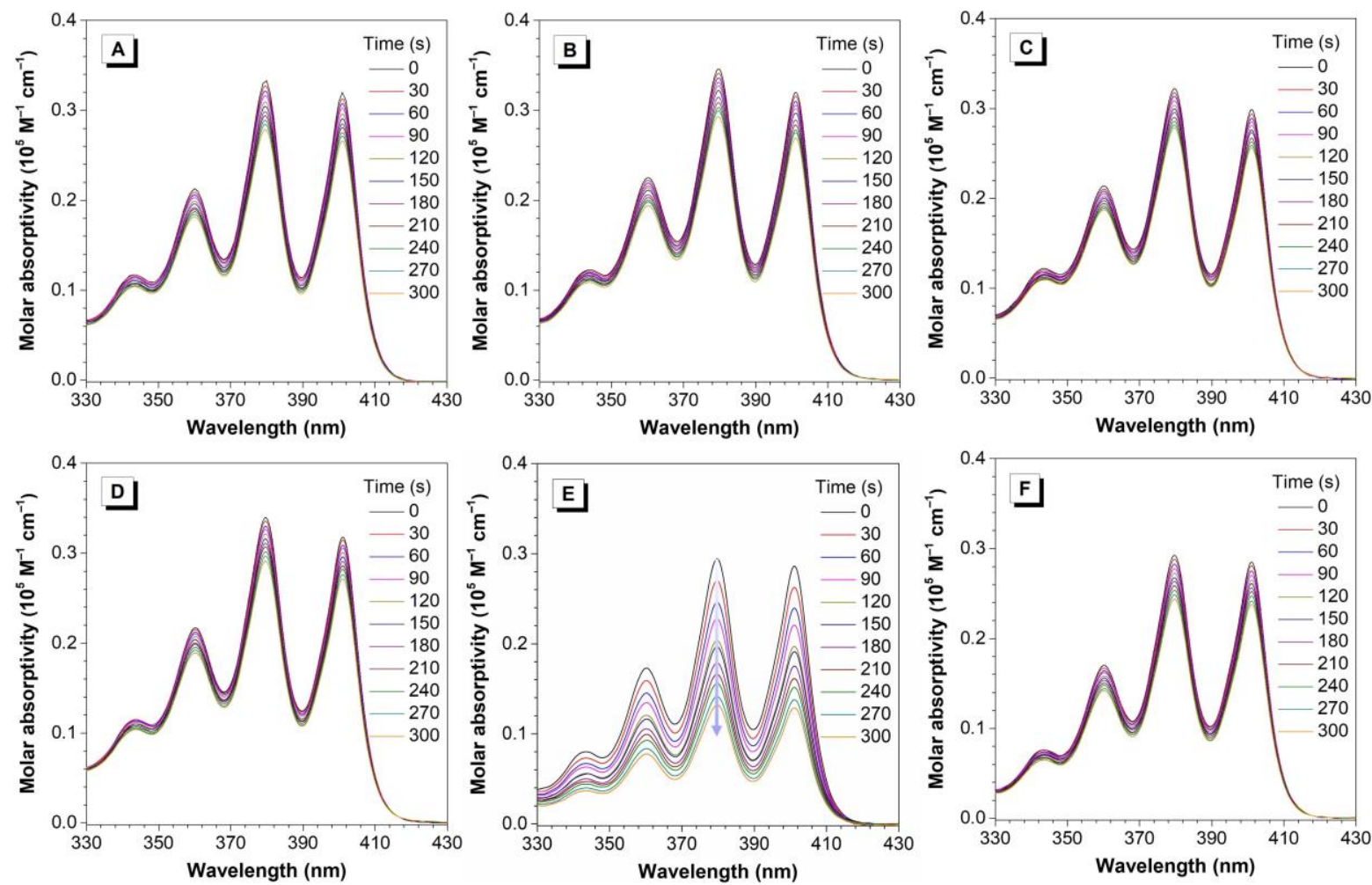
Figure S21. UV-vis absorption spectra of ABDA $(30 \mu \mathrm{M})$ in the presence of $1 \mu \mathrm{M}$ (A) PQ-TPA NPs, (B) PQ-TPAOC1 NPs, (C) PQ-TPAOC4 NPs, (D) PQ-TPAOC8 NPs, (E) RB NPs in PBS, and (F) blank, upon white light irradiation with $50 \mathrm{~mW} \mathrm{~cm}{ }^{-2}$ for different time.


Figure S22. PL spectra of SOSG $(5 \mu \mathrm{M})$ in the presence of $1 \mu \mathrm{M}$ (A) PQ-TPA NPs, (B) PQ-TPAOC1 NPs, (C) PQ-TPAOC4 NPs, (D) PQ-TPAOC8 NPs, (E) RB NPs in PBS, and (F) blank, upon white light irradiation with $50 \mathrm{~mW} \mathrm{~cm} \mathrm{~cm}^{-2}$ for different time. 

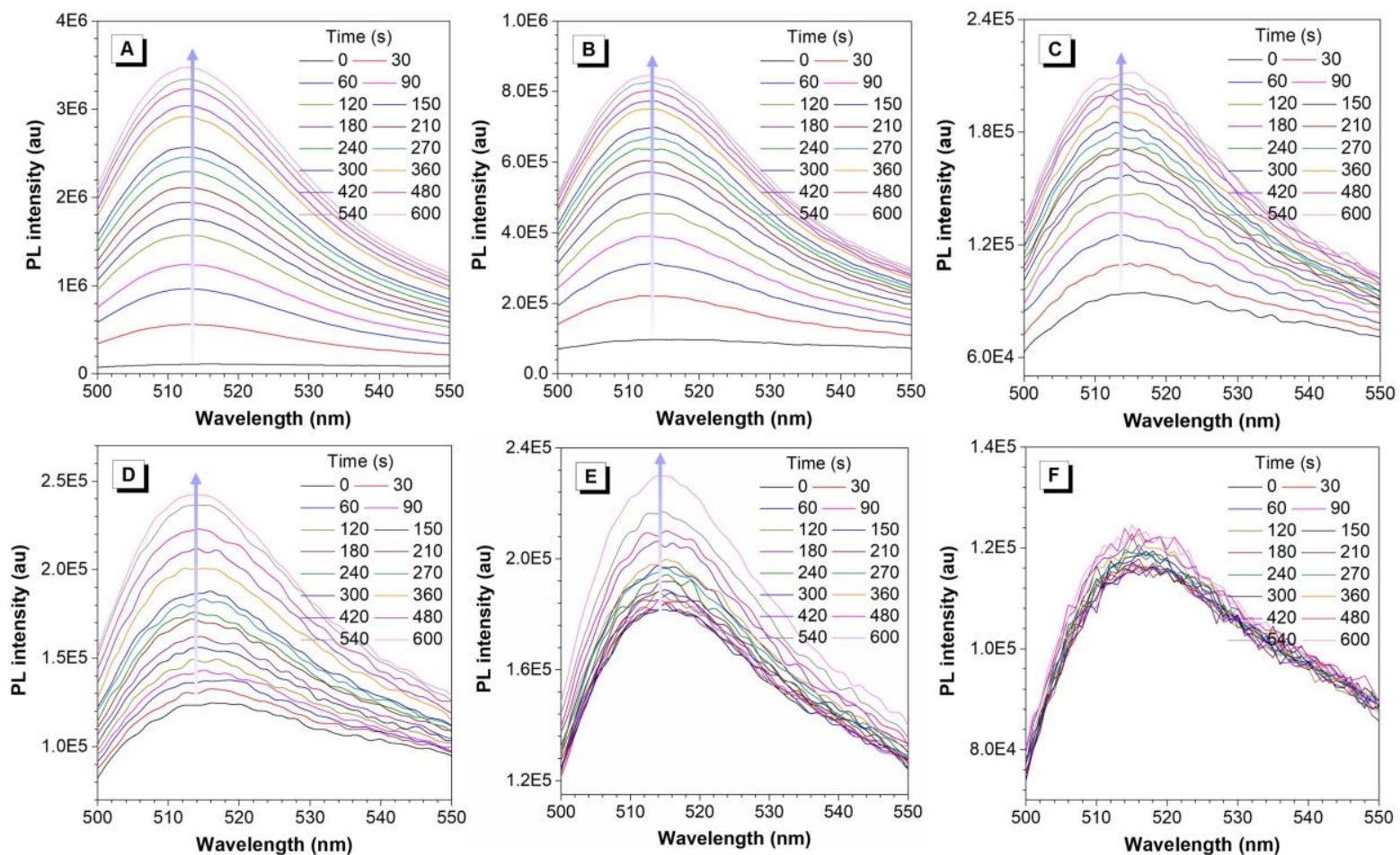

Figure S23. PL spectra of HPF $(5 \mu \mathrm{M})$ in the presence of $1 \mu \mathrm{M}$ (A) PQ-TPA NPs, (B) PQ-TPAOC1 NPs, (C) PQ-TPAOC4 NPs, (D) PQ-TPAOC8 NPs, (E) CV NPs in PBS, and (F) blank, upon white

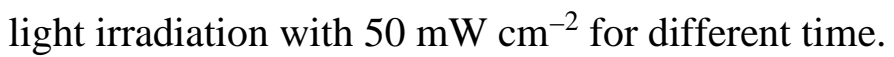

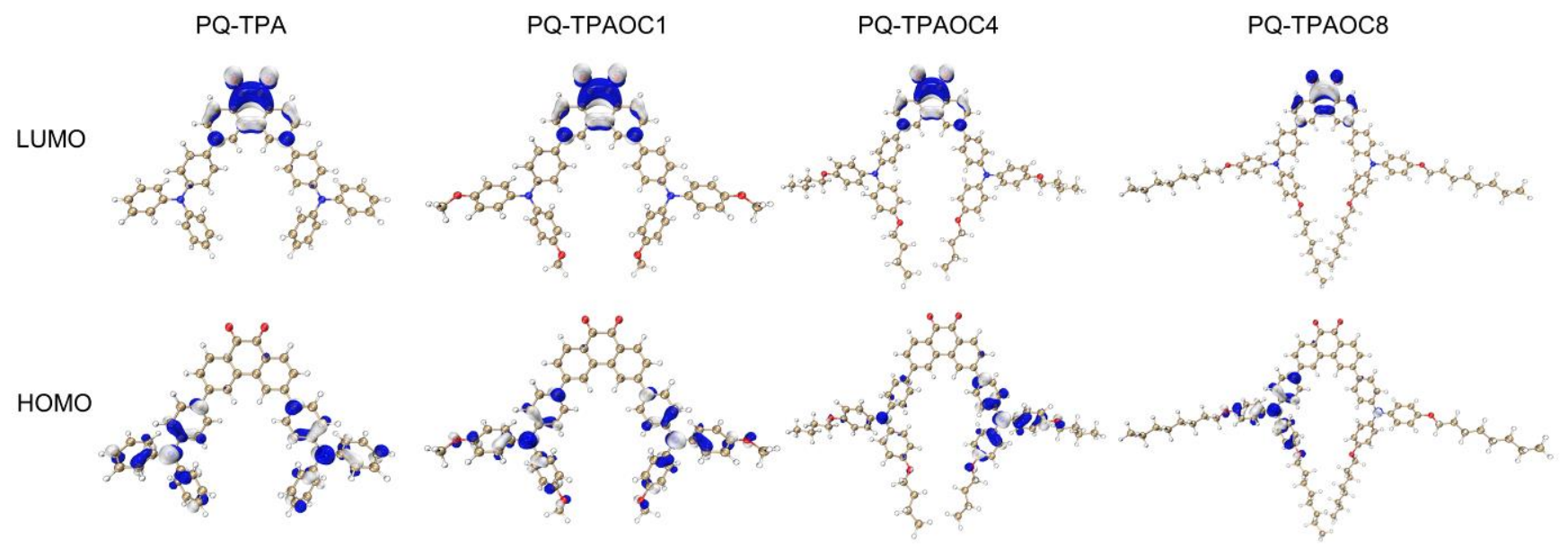

Figure S24. The calculated frontier orbital amplitude plots of PQ-TPA, PQ-TPAOC1, PQ-TPAOC4 and PQ-TPAOC8 in the ground state. 


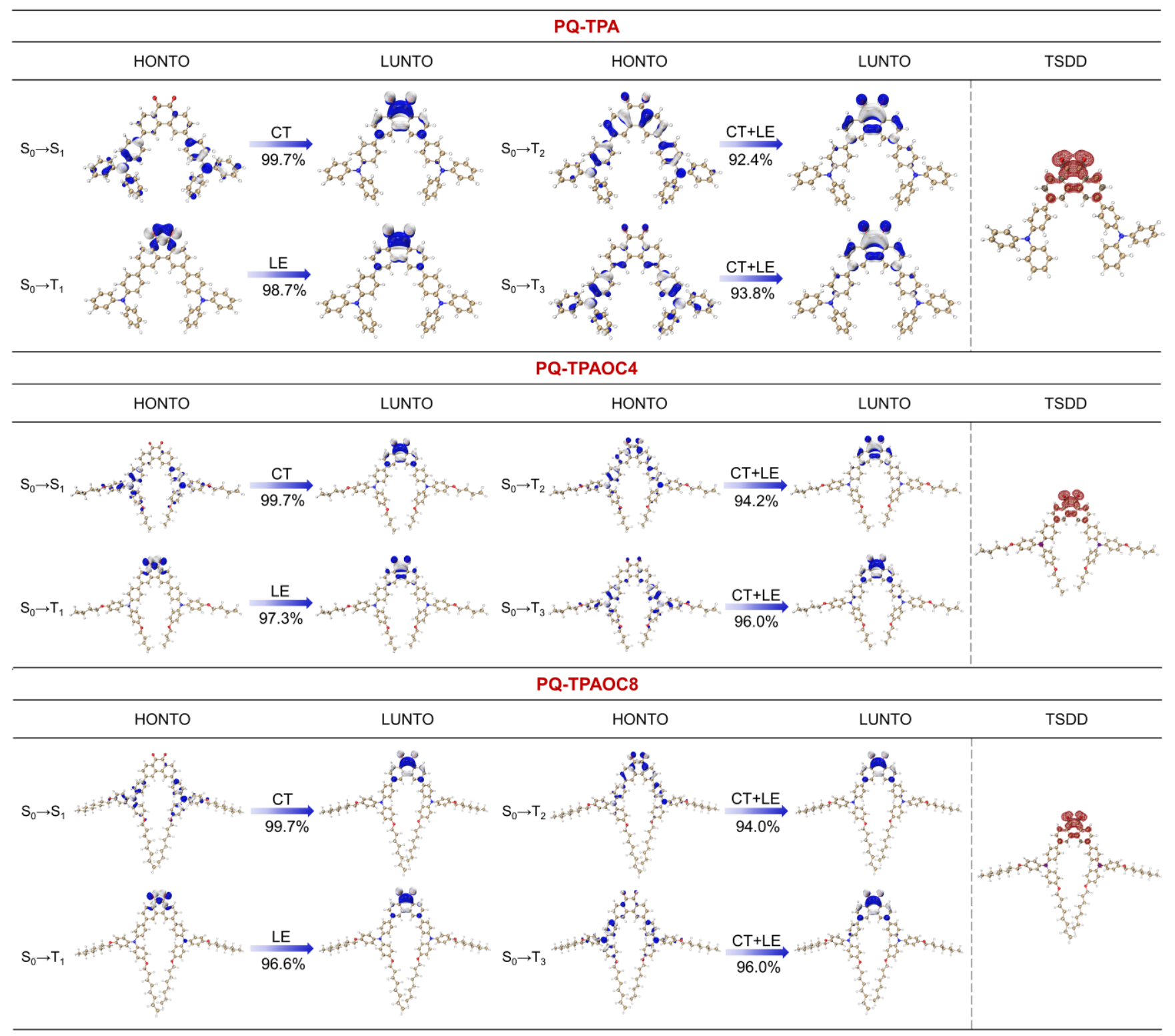

Figure S25. Natural transition orbitals, the eigenvalues of natural transition orbital pairs, transition characters and the spin density distributions of $\mathrm{T}_{1}$ states of PQ-TPA, PQ-TPAOC4 and PQ-TPAOC8. 



Figure S26. Electrostatic potential (ESP) mapped molecular van der Waals surface of (A) PQ-TPA, (B) PQ-TPAOC4 and (C) PQ-TPAOC8 (unit: $\mathrm{kcal} \mathrm{mol}^{-1}$ ). The green and orange tiny spheres represent the surface local minima and maxima of ESP, which are labeled by italic fonts marking both the values and the contributive atoms.

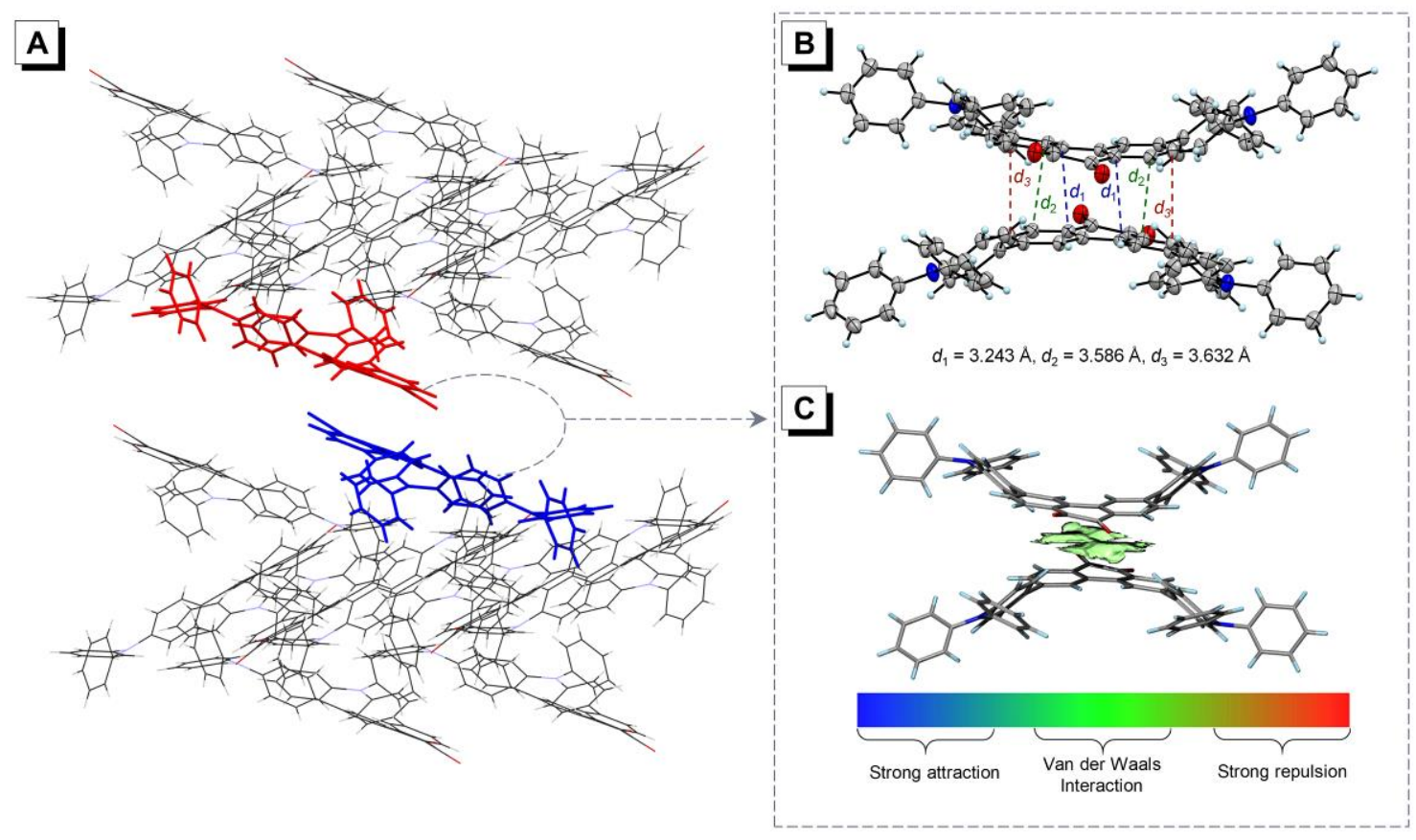

Figure S27. (A) Packing pattern of PQ-TPA in crystal; (B) the distance between the dimer in PQ-TPA crystal; (C) IGM analysis of the dimer in crystal. 

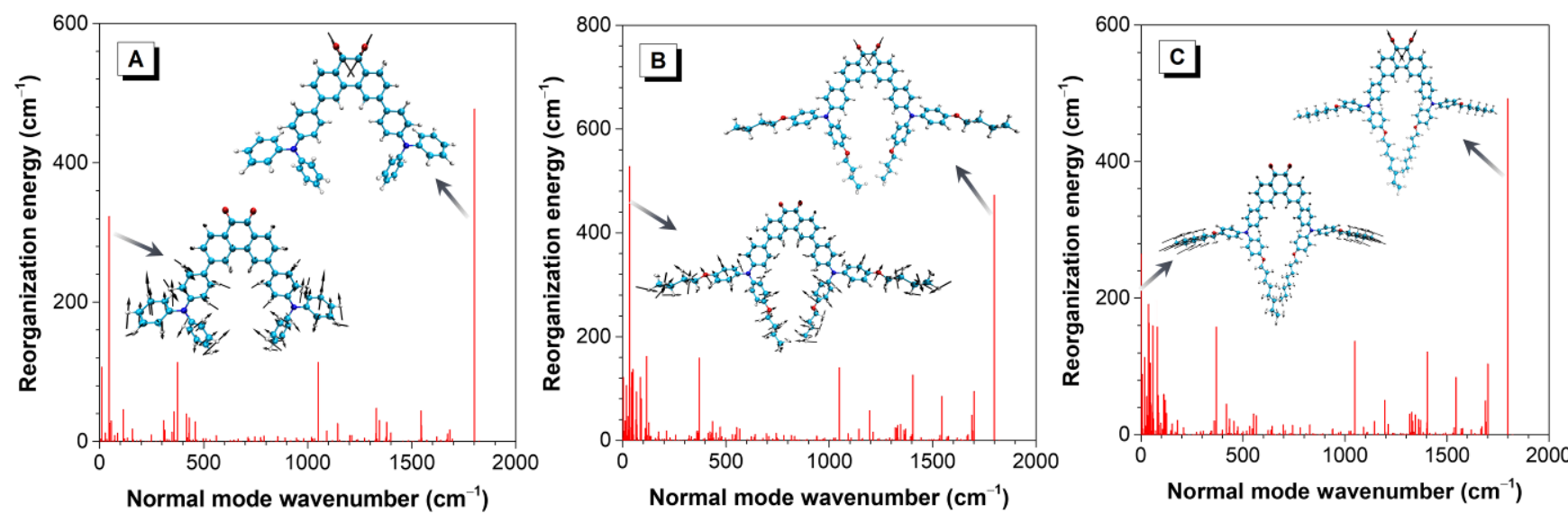

Figure S28. Calculated reorganization energies of (A) PQ-TPA, (B) PQ-TPAOC4 and (C)PQ-TPAOC8 versus normal mode frequencies. Inset: representative vibration modes.

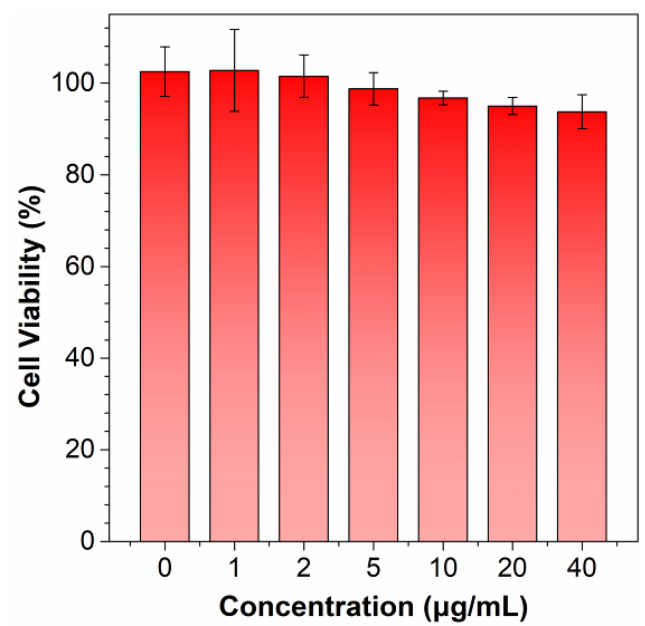

Figure S29. Cytotoxicity of PQ-TPAOC1 NPs on 4T1 cells determined by CCK8 assay. Cell viability data are shown as mean $\pm \operatorname{SD}(n=4)$.

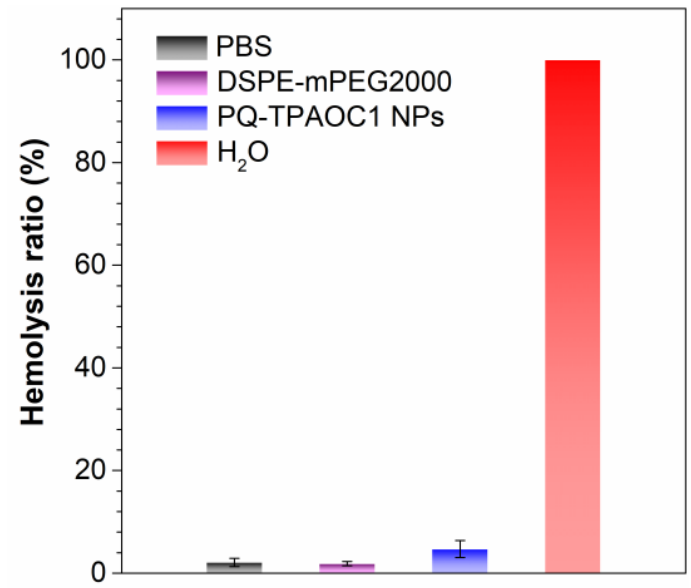

Figure S30. Hemolysis assay after incubated with DSPE-mPEG2000, PQ-TPAOC1 NPs, PBS (negative control), and ultrapure water (positive control) for $3 \mathrm{~h}$ in dark. The results are presented as the mean $\pm \mathrm{SD}(\mathrm{n}=3)$. 

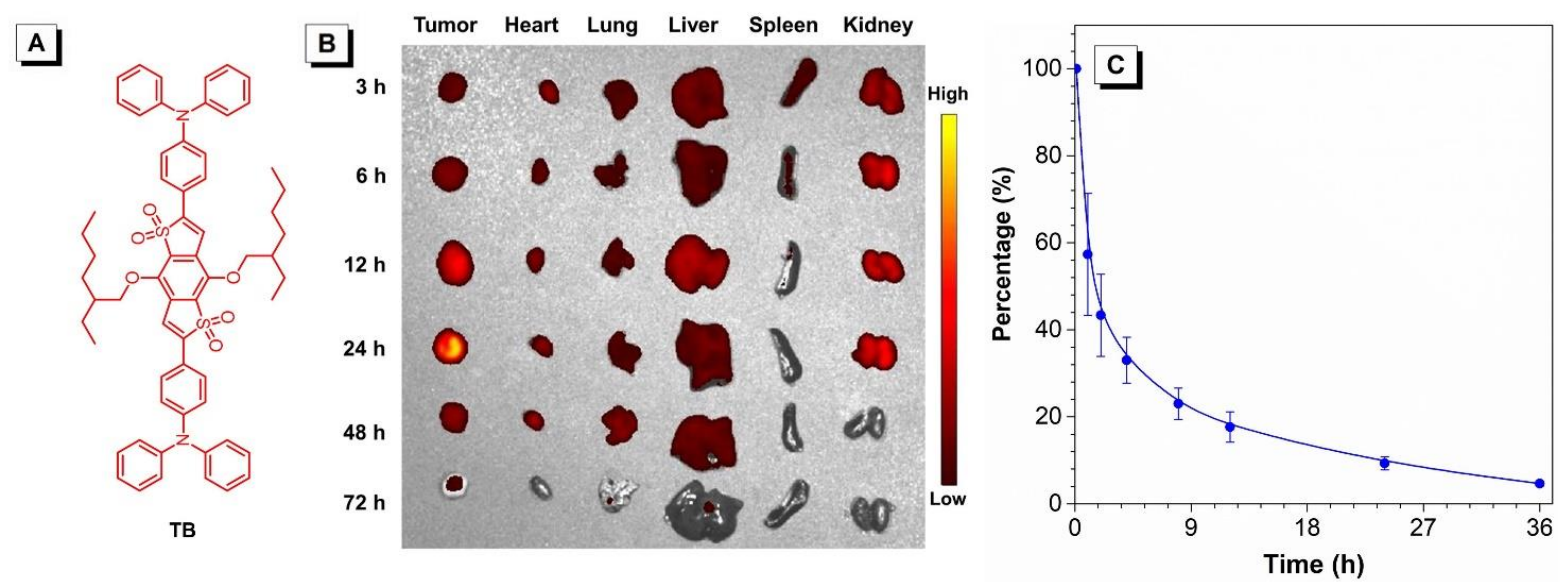

Figure S31. (A) The molecular structure of TB. (B) Time-dependent ex vivo fluorescence images of major organs and tumor tissues from the mice intravenously injected with TB/PQ-TPAOC1@DSPE-mPEG2000 NPs. $\quad$ (C) Pharmacokinetics of TB/PQ-TPAOC1@DSPE-mPEG2000 NPs in healthy mice. The data are presented as mean \pm SD $(n=$ $3)$.
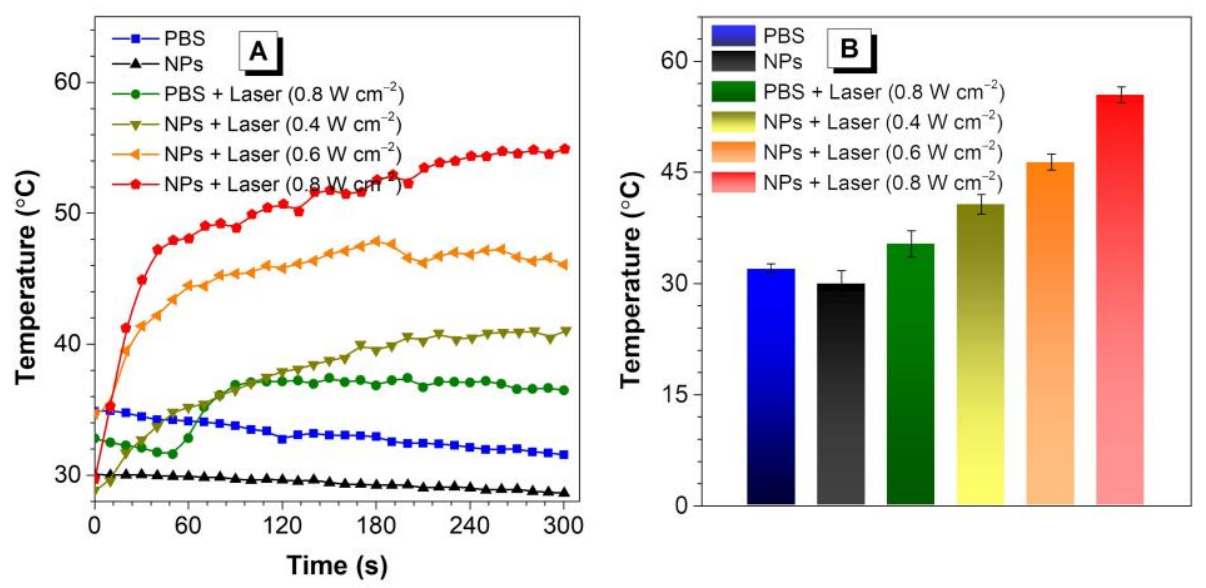

Figure S32. (A) Photothermal curves at the tumor sites and (B) the tumor region temperature of the mice treated intravenously with PBS $(200 \mu \mathrm{L})$ or PQ-TPAOC1 NPs $\left(200 \mu \mathrm{L}, 1.0 \mathrm{mg} \mathrm{mL}{ }^{-1}\right)$ without/with the $660 \mathrm{~nm}$ laser at different power densities irradiation for $5 \mathrm{~min}$, the data are shown as mean $\pm \mathrm{SD}(n=4)$. 


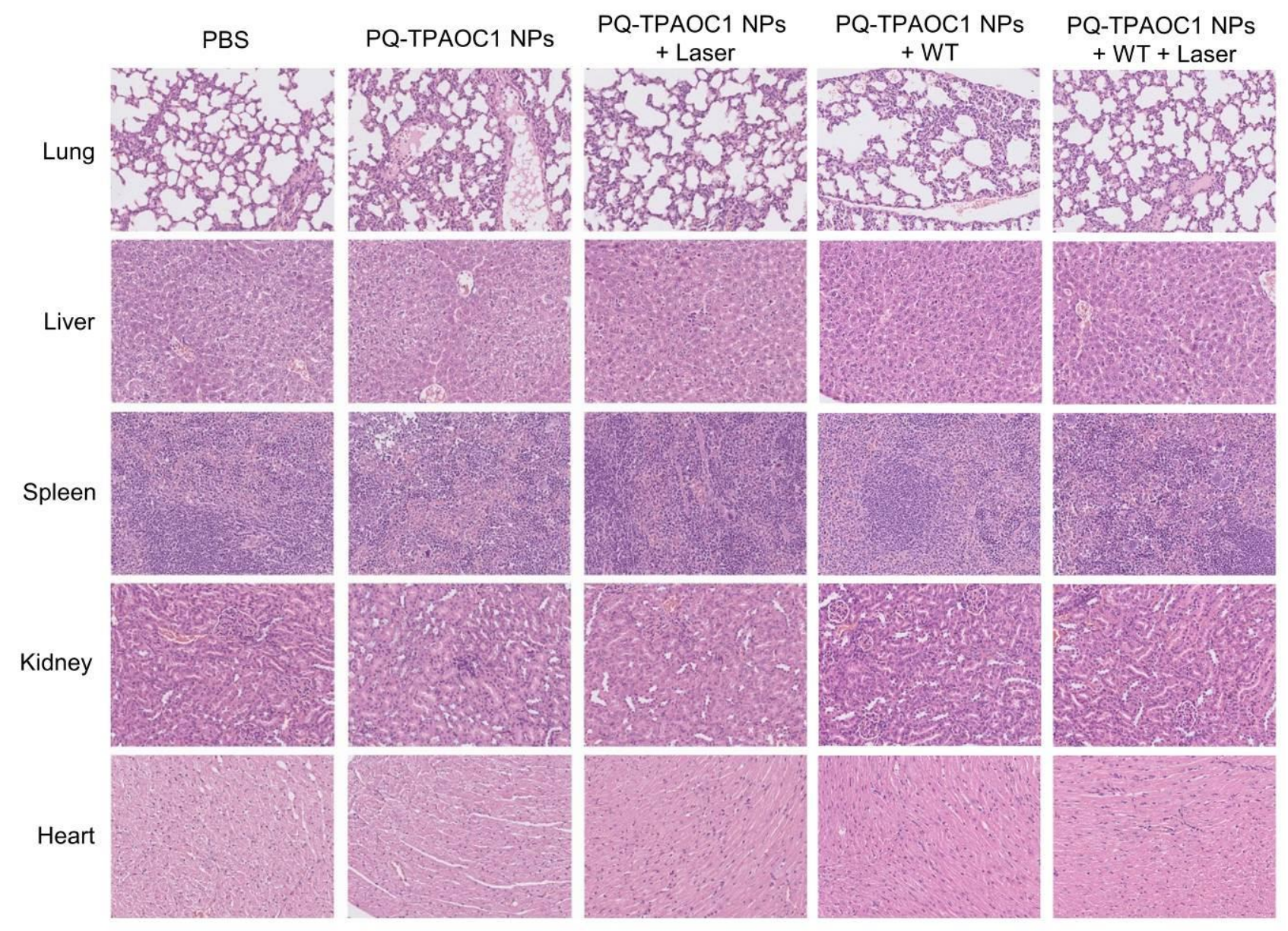

Figure S33. Histological $\mathrm{H} \& \mathrm{E}$ staining of various organ tissues in $4 \mathrm{~T} 1$ tumor-bearing mice after different treatments. 


\section{Supporting tables}

Table S1. Cyclic voltammetric data of PQ-TPA, PQ-TPAOC1, PQ-TPAOC4 and PQ-TPAOC8.

\begin{tabular}{lcccccccc}
\hline & \multicolumn{7}{c}{ Quinone/semiquinone redox couple } \\
\cline { 2 - 8 } & $\begin{array}{c}E_{\mathrm{pc}} \\
(\mathrm{mV})^{a}\end{array}$ & $\begin{array}{c}E_{\mathrm{pa}} \\
(\mathrm{mV})^{b}\end{array}$ & $\begin{array}{c}E_{1 / 2} \\
(\mathrm{mV})^{c}\end{array}$ & $\begin{array}{c}\Delta E_{\mathrm{p}} \\
(\mathrm{mV})^{d}\end{array}$ & $\begin{array}{c}E_{\mathrm{pc}}-E_{1 / 2} \\
(\mathrm{mV})\end{array}$ & $\begin{array}{c}I_{\mathrm{pc}} \\
(\mu \mathrm{A})^{e}\end{array}$ & $\begin{array}{c}I_{\mathrm{pa}} \\
(\mu \mathrm{A})^{f}\end{array}$ & $I_{\mathrm{pa}} / I_{\mathrm{pc}}$ \\
\hline PQ-TPA & -1115 & -1037 & -1076 & 78 & -39 & 17.2 & 16.2 & 0.94 \\
PQ-TPAOC1 & -1138 & -1063 & -1101 & 75 & -37 & 15.1 & 14.3 & 0.95 \\
PQ-TPAOC4 & -1136 & -1070 & -1103 & 66 & -33 & 7.4 & 6.8 & 0.92 \\
PQ-TPAOC8 & -1131 & -1059 & -1095 & 72 & -36 & 6.2 & 5.8 & 0.94 \\
\hline All
\end{tabular}

All potentials are reported $v s . \mathrm{Fc} / \mathrm{Fc}^{+}$redox couple. ${ }^{a}$ Cathodic peak potential. ${ }^{b}$ Anodic peak potential. ${ }^{c}$ Half-wave potential. ${ }^{d} \Delta E_{\mathrm{p}}=E_{\mathrm{pa}}-E_{\mathrm{pc} .}{ }^{e}$ Cathodic peak current. ${ }^{f}$ Anodic peak current.

Table S2. Photophysical properties of PQ-TPA, PQ-TPAOC1, PQ-TPAOC4 and PQ-TPAOC8.

\begin{tabular}{|c|c|c|c|c|c|c|c|c|}
\hline & \multicolumn{3}{|c|}{$\mathrm{THF}^{a}$} & \multicolumn{2}{|c|}{ Toluene $^{b}$} & \multicolumn{3}{|c|}{$\mathrm{NPs}^{c}$} \\
\hline & $\begin{array}{c}\lambda_{\mathrm{abs}} \\
(\mathrm{nm})\end{array}$ & $\begin{array}{c}\lambda_{\mathrm{em}} \\
(\mathrm{nm})\end{array}$ & $\begin{array}{c}\Phi_{\mathrm{PL}} \\
(\%)^{d}\end{array}$ & $\begin{array}{c}\lambda_{\mathrm{em}} \\
(\mathrm{nm})\end{array}$ & $\begin{array}{c}\Phi_{\mathrm{PL}} \\
(\%)^{d}\end{array}$ & $\begin{array}{c}\lambda_{\mathrm{abs}} \\
(\mathrm{nm})\end{array}$ & $\begin{array}{c}\lambda_{\mathrm{em}} \\
(\mathrm{nm})\end{array}$ & $\begin{array}{c}\Phi_{\mathrm{PL}} \\
(\%)^{d}\end{array}$ \\
\hline PQ-TPA & 458 & 690 & 0.4 & 636 & 4.4 & 512 & 682 & 0.6 \\
\hline PQ-TPAOC1 & 491 & - & 0.3 & 676 & 1.2 & 545 & 686 & 0.4 \\
\hline PQ-TPAOC4 & 495 & - & 0.4 & 685 & 1.0 & 589 & 687 & 0.4 \\
\hline PQ-TPAOC8 & 495 & - & 0.3 & 689 & 1.1 & 588 & 690 & 0.3 \\
\hline
\end{tabular}

${ }^{a}$ THF solution $\left(10^{-5} \mathrm{M}\right) .{ }^{b}$ Toluene solution $\left(10^{-5} \mathrm{M}\right) .{ }^{c}$ The as-prepared NPs in water. ${ }^{d}$ Absolute PL quantum yield determined by a calibrated integrating sphere at room temperature.

Table S3. Reorganization energies $\left(\mathrm{cm}^{-1}\right)$ from the bond length, bond angle, and dihedral angle of PQ-TPA, PQ-TPAOC1, PQ-TPAOC4 and PQ-TPAOC8.

\begin{tabular}{lcccc}
\hline & PQ-TPA & PQ-TPAOC1 & PQ-TPAOC4 & PQ-TPAOC8 \\
\hline Bond length & 1069.4 & 1697.6 & 1696.9 & 1702.8 \\
Bond angle & 421.1 & 329.4 & 681.2 & 519.2 \\
Dihedral angle & 608.9 & 2004.3 & 1916.3 & 1990.5 \\
Total & 2099.4 & 4031.3 & 4294.4 & 4212.5 \\
\hline
\end{tabular}

